\title{
WestVirginiaUniversity
}

THE RESEARCH REPOSITORY @ WVU

Graduate Theses, Dissertations, and Problem Reports

2020

\section{Characterizing premixed syngas combustion in micro-channels}

\author{
Sunita Pokharel \\ West Virginia University, sp0078@mix.wvu.edu
}

Follow this and additional works at: https://researchrepository.wvu.edu/etd

Part of the Aerodynamics and Fluid Mechanics Commons, Heat Transfer, Combustion Commons, and the Propulsion and Power Commons

\section{Recommended Citation}

Pokharel, Sunita, "Characterizing premixed syngas combustion in micro-channels" (2020). Graduate Theses, Dissertations, and Problem Reports. 7510.

https://researchrepository.wvu.edu/etd/7510

This Thesis is protected by copyright and/or related rights. It has been brought to you by the The Research Repository @ WVU with permission from the rights-holder(s). You are free to use this Thesis in any way that is permitted by the copyright and related rights legislation that applies to your use. For other uses you must obtain permission from the rights-holder(s) directly, unless additional rights are indicated by a Creative Commons license in the record and/ or on the work itself. This Thesis has been accepted for inclusion in WVU Graduate Theses, Dissertations, and Problem Reports collection by an authorized administrator of The Research Repository @ WVU. For more information, please contact researchrepository@mail.wvu.edu. 


\section{Characterizing Premixed Syngas Combustion in Micro-channels}

\section{Sunita Pokharel}

Thesis submitted to the

Benjamin M. Statler College of Engineering and Mineral Resources

at West Virginia University

in partial fulfillment of the requirements for the degree of

Master of Science in

Aerospace Engineering

V'yacheslav Akkerman, Ph.D., Chair

Mohsen Ayoobi, Ph.D.

Hailin Li, Ph.D.

Department of Mechanical and Aerospace Engineering

Morgantown, West Virginia

2020

Keywords: micro-combustion; syngas; repeated ignition and extinction; numerical simulation; flame instabilities; Reacting flows; Computational fluid dynamics (CFD);

Copyright (C) 2020 Sunita Pokharel 


\section{Abstract \\ Characterizing Premixed Syngas Combustion in Micro-channels}

\section{Sunita Pokharel}

Increasing demands in the next-generation portable power-generation devices such as unmanned aerial vehicles (UAV), microsatellite thrusters, micro-chemical reactors and sensors calls for fuels with high specific energy and low emissions to meet the current demand of green energy. Fuellean synthesis gas (syngas) meets both these requirements exhibiting a promising route to a clean and green environment. Thus, it is of critical importance to characterize syngas combustion and understand its properties in the micro-combustion industry. In addition to complicated flame dynamics in microscale systems, varying the syngas-fuel mixture composition as well as the boundary conditions and geometry of a combustor significantly affect the burning process in the system. This work investigates the characteristics of a premixed syngas flame in a horizontal twodimensional micro-channel of length $20 \mathrm{~mm}$ and half-width $1 \mathrm{~mm}$ by means of computational simulations using the ANSYS Fluent commercial software. A fixed temperature gradient is employed at the upper wall such that the temperature grows linearly, from $300 \mathrm{~K}$ at the inlet to $1500 \mathrm{~K}$ at the outlet to account for the conjugate heat transfer. The chemical kinetics of the combustion process is imitated by the San Diego mechanism with 46 species and 235 reactions, which is implemented using the Chemkin mechanism in ANSYS Fluent. Stoichiometric premixed burning of syngas comprised of carbon monoxide $(\mathrm{CO})$, methane $\left(\mathrm{CH}_{4}\right)$ and hydrogen $\left(\mathrm{H}_{2}\right)$, with various compositions and inlet fuel-air flow velocities, is considered. Various properties of the combustion process such as ignition, stabilization and extinction are characterized. It is further shown how instabilities can be eliminated by increasing the inlet flow velocity to form a stable, stationary flame. As a result, it is demonstrated how various combustion characteristics depend on the inlet velocity and composition of a syngas mixture. 


\section{ACKNOWLEDGMENTS}

I want to thank Dr. Akkerman and Dr. Ayoobi for providing invaluable assistance on this project. I also want to thank Dr. Li for his permanent support and agreeing to be a part of my committee.

I would like to acknowledge the use of WVU's computational and educational resources and want to thank Dr. Akkerman again for providing me with all the resources such as the computing system, research materials and most importantly a platform for conducting various research and exploring our capability.

I would also like to thank all the members of my CFD Lab and WVU-MAE Department for their immense support during my academic journey.

Finally, I would like to thank all my family and my friends from Nepal and here in the USA for their unwavering support through all the thick and thins. 


\section{Table of contents}

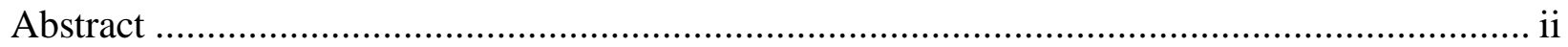

ACKNOWLEDGMENTS ...................................................................................... ii

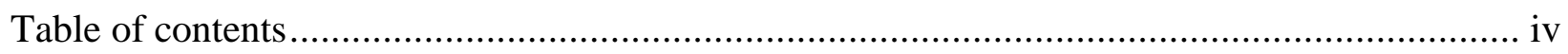

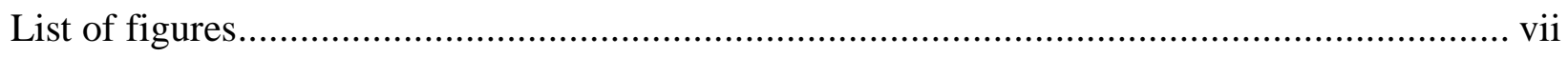

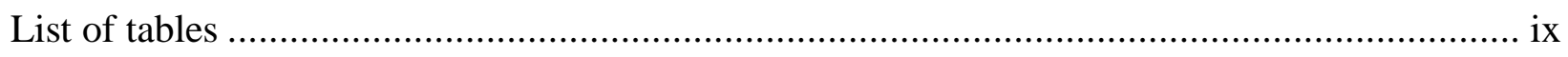

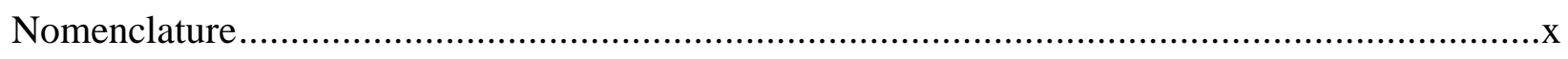

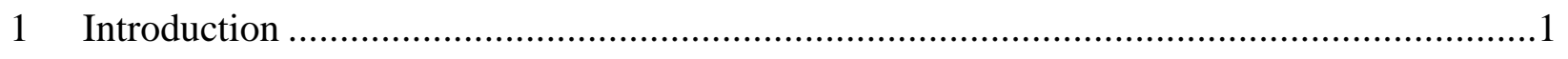

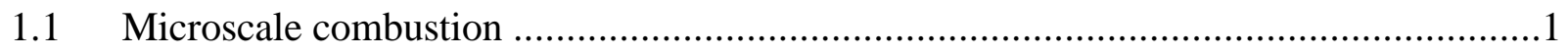

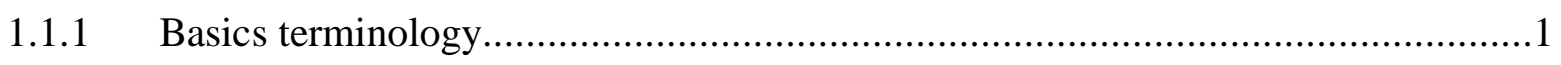

1.1.2 Application of micro-scale combustion ...................................................

1.1.3 Effects on combustion characteristics for microscale system ............................

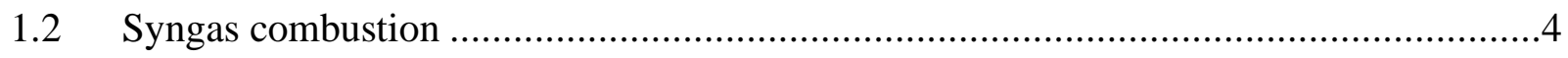

1.2.1 Production of syngas ...........................................................................

1.2.2 Effects of composition on syngas combustion ..........................................

1.2.3 Advantages of syngas combustion..........................................................

1.2.4 Challenges in syngas combustion ......................................................

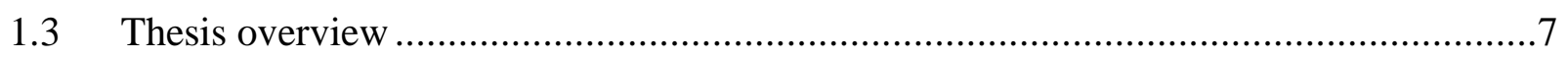

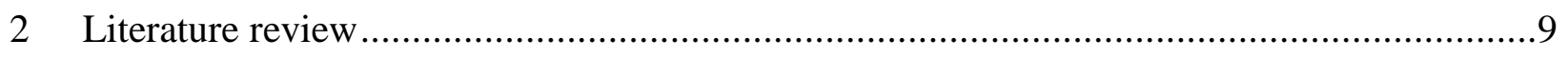

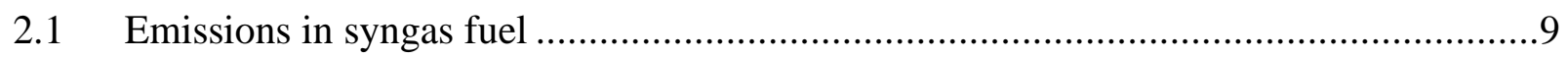

2.2 Combustion study at microscale system for hydrogen/air mixture ........................... 10

2.3 Combustion study at microscale system for methane/air mixture ...........................11

2.4 Studies of propane-air combustion in microscale systems...................................... 12

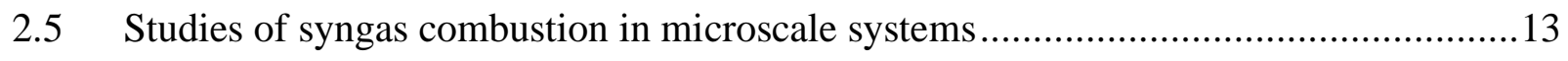




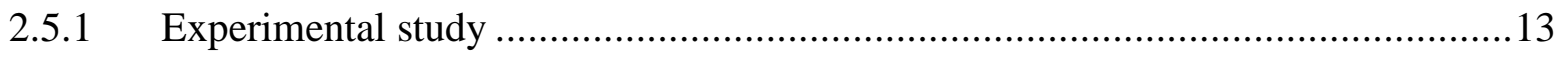

2.5.2. Computational study ........................................................................ 16

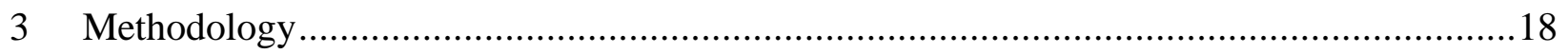

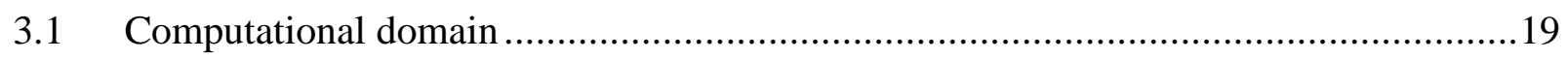

3.1.1 Grid resolution .............................................................................. 20

3.1.2 Time resolution............................................................................... 21

3.2 Chemical model .................................................................................... 21

$3.3 \quad$ Numerical model.....................................................................................22

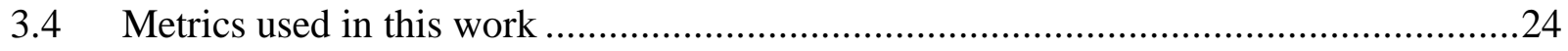

3.4.1 Heat release rate ................................................................................. 24

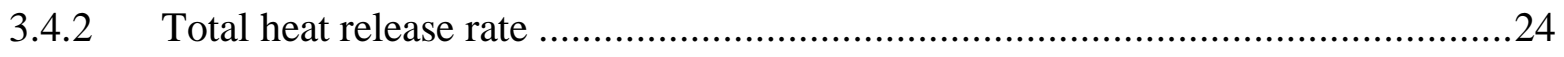

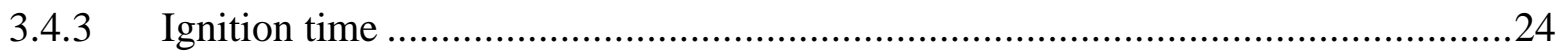

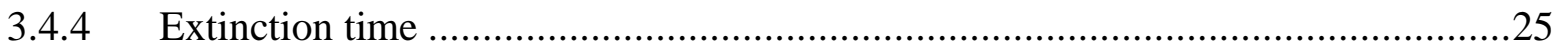

3.4.5 Ignition and stable flame: ...............................................................25

3.4.6 Ignition location and length.................................................................25

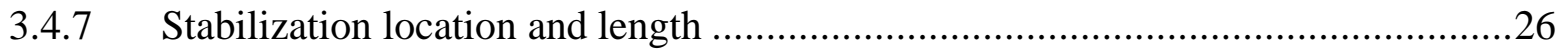

3.4.8 Flame with repetitive ignition extinction period ......................................27

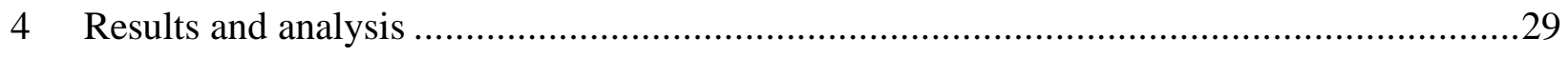

4.1 Case 1: Analysis of flame characteristics with respect to inlet velocity ....................29

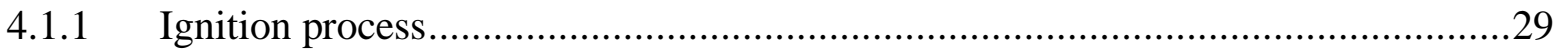

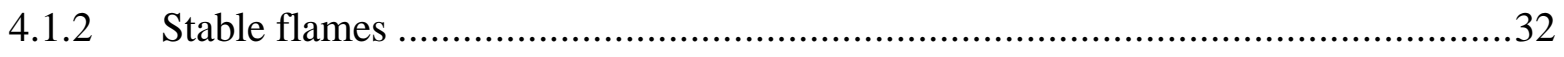

4.1.3 Flames with repetitive ignition \& extinction (FRIE) ....................................33

4.2 Case 2: Analysis of flame characteristics with varying composition ........................35

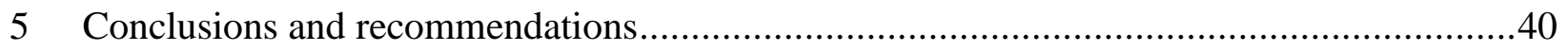




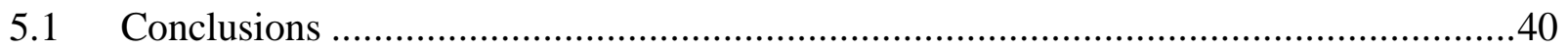

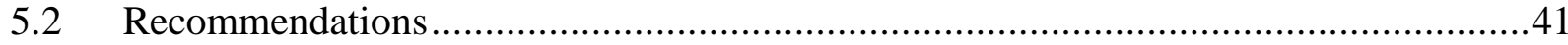

$5.3 \quad$ Future works ...................................................................................... 41

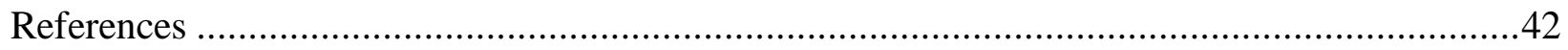




\section{List of figures}

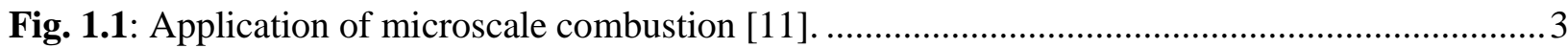

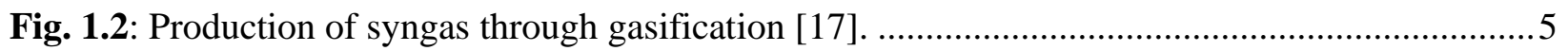

Fig. 2.1: Impact of syngas composition on $\mathrm{CO}(\mathrm{a}), \mathrm{NO}_{\mathrm{x}}(\mathrm{b})$ and $\mathrm{CO}_{2}$ (c) emissions and burning efficiency (d) [16].

Fig. 2.2: Global stability diagram for microscale premixed combustion for hydrogen-air fuel [26]. . 11

Fig. 2.3: Experimentally deduced stability maps. Circles: stationary modes, triangles: oscillatory modes. Filled symbols: modes with nearly symmetric shapes, open symbols: asymmetric modes. Red symbols: $\phi=0.42$, blue symbols: $\phi=0.30$, green symbols: $\phi=0.25$. Dashed lines demarcate regions of stationary (right) and oscillatory (left) modes, for each investigated $\phi[33]$.

Fig. 2.4: The laminar flame velocity versus the equivalence ratio (a), temperature ratio (b) and $\mathrm{CO}$ content (c) [20].

Fig. 2.5 : (a) Time variant total heat release rate in the domain against simulation time. It is noted that in addition to cases 1-1 and 2-4, this figure includes 3 more inlet velocities for each mixture for the sake of comparison and to indicate the importance of inlet velocity on the flames behavior [35]...... 16

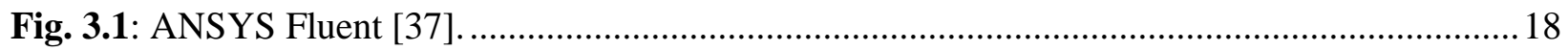

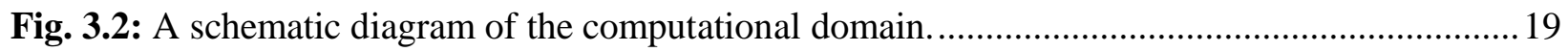

Fig. 3.3: The grid resolution test: A comparison of the cases with various mesh sizes for the inlet velocity of $1 \mathrm{~m} / \mathrm{s}$ 20

Fig. 3.4: The time resolution test: comparison between the runs at various time steps for the inlet velocity of $1 \mathrm{~m} / \mathrm{s}$.

Fig. 3.5: The temperature distribution along the $x$-axis (a) and the temperature color snapshot (b) at the time of ignition for the inlet flow velocity of $1 \mathrm{~m} / \mathrm{s}$.

Fig. 3.6: The temperature variation for the stabilized flame with the inlet flow velocity of $1 \mathrm{~m} / \mathrm{s}: \ldots .27$

Fig. 3.7: The FRIE period at the inlet velocity of $1 \mathrm{~m} / \mathrm{s}$. 27

Fig. 4.1: The total heat release rate $\left(H R R_{T}\right)$ versus time for the inlet velocity of $1.0 \mathrm{~m} / \mathrm{s}$. 30 
Fig. 4.2: Temperature distribution at selected time steps during the ignition process (the inlet velocity is $1 \mathrm{~m} / \mathrm{s}$ ). .31

Fig. 4.3: The total heat release rate $\left(H R R_{T}\right)$ versus time for the inlet velocities resulting in a stable flame. .32

Fig. 4.4: $H R R_{T}$ versus time for a flame with repetitive ignition/extinction (here, the inlet velocity is $0.2 \mathrm{~m} / \mathrm{s})$.

Fig. 4.5: Temperature contours at selected time steps representing flames with FRIE for the inlet velocity of $0.2 \mathrm{~m} / \mathrm{s}$. .34

Fig. 4.6: $H R R_{T}$ versus time for the syngas mixture from Table 3.1 at various inlet velocities. .36

Fig. 4.7: $H R R_{T}$ versus time for the stable flame cases. .38

Fig. 4.8: $H R R_{T}$ versus time for the FRIE cases 39 


\section{List of tables}

Table 1.1: Syngas composition of different feedstock and gasifiers [22]. .............................6

Table 3.1: Syngas mixture compositions studied in this work ............................................22

Table 4.1: Classification of flame behavior for various inlet velocities..............................29

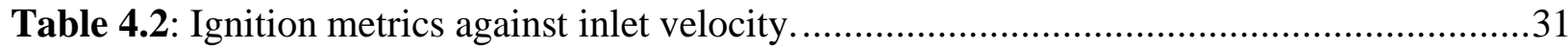

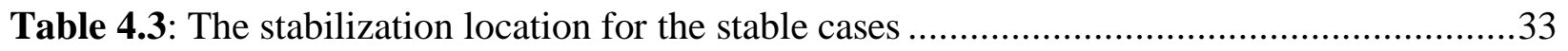

Table 4.4: The FRIE period for the corresponding inlet velocities...................................35

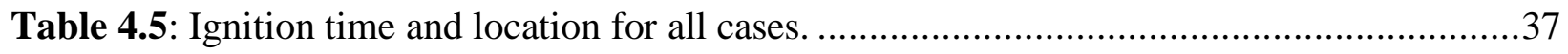

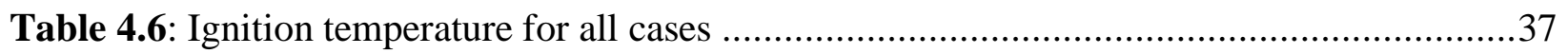

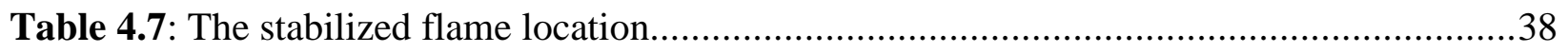

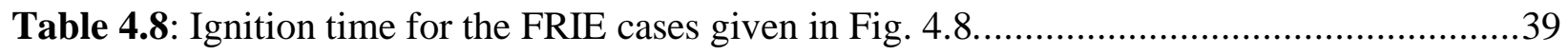




\section{Nomenclature}

$\begin{array}{ll}\text { CFD } & \text { Computational fluid dynamics } \\ \text { FRIE } & \text { Flames with repetitive ignition/extinction } \\ \phi & \text { Equivalence ratio } \\ t_{i g} & \text { Ignition time } \\ t_{e x} & \text { Extinction time } \\ \tau_{F R I E} & \text { FRIE period } \\ x_{i g-s t}, x_{i g-e} & \text { Ignition location } \\ \Delta x_{\text {ig }} & \text { Ignition length, i.e. } x_{i g-e}-x_{i g-s t} \\ H R R & \text { Local heat release rate } \\ H R R_{T} & \text { Total heat release rate } \\ x_{S z-s t}, x_{S z-e} & \text { Location of a stable flame } \\ \Delta x_{\mathrm{sz}} & \text { Flame span, i.e. } x_{S z-e}-x_{S z-s t} \\ R_{i} & \text { Net rate of production of species } i \\ S_{i} & \text { Rate of creation by addition } \\ Y_{i} & \text { Local mass fraction of species } i \\ \overrightarrow{J_{l}} & \text { Diffusion flux of species } i \\ \rho & \text { Density of the mixture } \\ \overrightarrow{\mathrm{v}} & \text { Velocity } \\ & \end{array}$




\section{Introduction}

\subsection{Microscale combustion}

Combustion is an exothermic chemical reaction between a combustible material (such as a fuel) and an oxidizer (such as air, oxygen, fluorine) producing heat, light, burnt mixture, oxides and exhaust gases. Chemical reactions in a combustion process have highly nonlinear reaction rates, and they are self-sustaining until thermal equilibrium is attained which occurs when the energy of the reactants is equal to that of the products. Combustion can proceed at various scales depending on the burner size and geometry, starting from large-scale rocket propulsion engines and ending with micro-thrusters. Micro-combustion can be defined in terms of its physical length [1], flame quenching diameter [2] and the size of a combustor as compared to the conventional large-sized devices used for the same purpose [3,4]. Here, microscale combustion is referred to as combustion occurring at the scales ranging from micrometers to centimeters, with micropower generation from milliwatts to watts.

\subsubsection{Basics terminology}

Premixed flame and flame front: Combustion can be categorized into two types depending on how the fuel and the oxidizer are being mixed, namely as premixed and non-premixed combustion. In premixed combustion, the fuel and oxidizer are mixed before the reaction starts, and they are mixed at a molecular level. In non-premixed combustion, the fuel and the oxidizer mix after they enter the ignition or reaction zone. The excessive release of energy in a very thin zone during this process is known as flame fronts which are self-propagating inducing high-temperature variance between the burnt and unburnt gases. Combustion occurs as a front propagating into the unburnt reactants. This is occurred only during deflagrations where combustion is in a subsonic regime and not during detonation where combustion lies in a supersonic regime.

Steady and unsteady flow: A steady flow is a flow whose properties such as the velocity, pressure, etc. do not vary with time, while an unsteady flow is those whose properties vary with time. Often in combustion, during the initial stage of the process, the flow is unsteady and it gains steady state as soon as the chemical equilibrium is obtained. 
Flammability limit: A limit determining a range of concentration of the material at which the material is combustible, or flammable, i.e., is capable to be burned. It is defined theoretically and experimentally for one-dimensional, planar and unstretched flame.

Quenching diameter: When the fuel-air mixture is in a channel, the heat losses from the burning system to the wall are usually not significant if the system is large-scale, but in case of microchannels, there is a limitation in the diameter of the channel allowing flame propagation such that if the channel diameter is further reduced, then the flame front quenches or extinguishes. This limiting diameter is known as the quenching diameter and it depends on the mixture composition.

Residence time: Residence time in a combustion process is the time accessible for the combustion system for chemical reaction to initiate and proceed. It depends on the size of the combustion system and the velocity of the reactant flow.

Equivalence ratio: Equivalence ratio $(\phi)$ is defined as the actual fuel-to-oxidizer ratio scaled by the stochiometric fuel-to-oxidizer ratio,

$$
\phi=\frac{\text { fuel-to-oxidizer ratio }}{(\text { fuel-to-oxidizer ratio })_{s t}}=\frac{m_{f u e l} / m_{o x}}{\left.\left(m_{f u e l} / m_{o x}\right)\right)_{s t}} .
$$

This is the measure of whether the fuel-oxidizer mixture is fuel-lean $(\phi<1$, excess of oxygen, so the fuel is oxidized completely), or stochiometric ( $\phi=1$, so the fuel and oxidizer are balanced and consumed completely) or fuel-rich ( $\phi>1$, excessive fuel with a limit of oxygen to provide complete burning).

\subsubsection{Application of micro-scale combustion}

Due to the increasing demand for highly effective miniaturized and portable power generation technologies, microscale and mesoscale combustion has been an attraction for years now. Since these devices demand low weight and durability, micro-combustion has been applicable because of the high specific energy stored in the fuel $[5,6]$. Thus, micro-combustion has various applications in different research fields such as microelectronics [7], biomechanics, chemical propulsion, etc., with such devices as micro-satellite thrusters [8], micro-chemical reactors/sensors [9, 10]; miniaturized unmanned aerial vehicles (UAV) which are summarized in Fig. 1.1. 


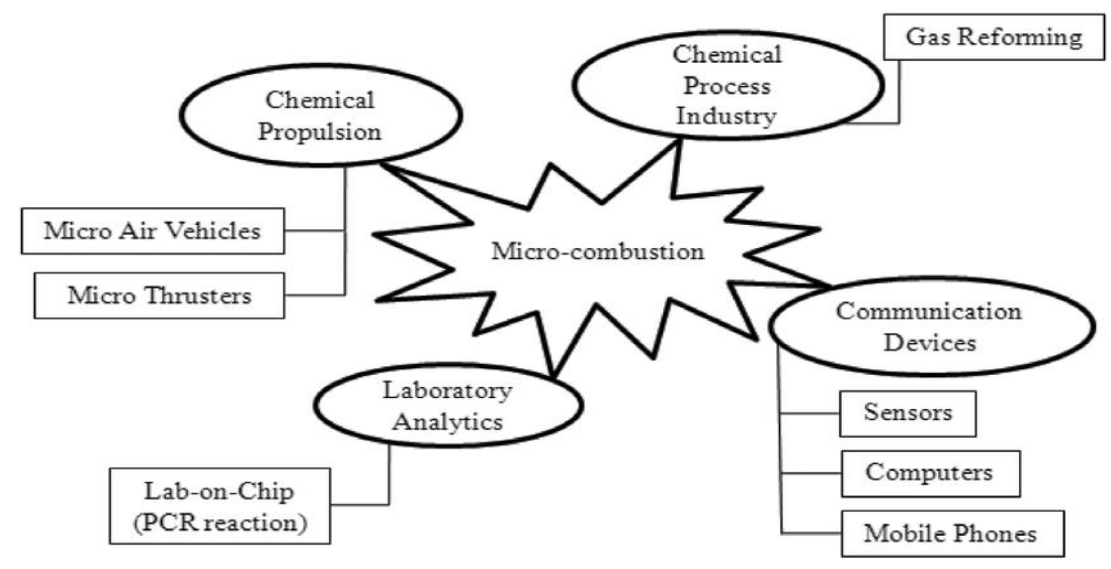

Fig. 1.1: Application of microscale combustion [11].

\subsubsection{Effects on combustion characteristics for microscale system}

The dynamics is significantly different from the large-scale combustion system when it reduces to micro and mesoscale. Thus, the proper study is required for microscale combustion. As the size of a system decreases, the Reynolds number of this system also diminishes: Indeed, $R e=\rho u L / \mu$, where $\rho$ is the density of the fluid, $u$ is the flow speed, $L$ is the characteristic length of the system and $\mu$ is the dynamic viscosity of the medium. All other parameters such as $\rho$ and $u$ depend on the input and $\mu$ depends on the boundary conditions, except characteristic length which depends on the dimension of the system, thus making lower ranges of $R e$ for microscale combustion which means the flow becomes dominantly laminar. This means very low to no turbulence mixing; hence mixing is accompanied by diffusion only.

Further, when any system or device becomes smaller or thinner its surface area to volume ratio increases. For the system designed for power production, this is a big disadvantage as it promotes the heat losses from the surface on a very high level to impact the efficiency of the combustor. However, this can be advantageous to the system used for the heat transfer operation. Thus, the conjugate heat loss on the surface of the system or channel is another important parameter that needs to be characterized in a microscale combustion system as this will directly influence the combustion dynamics and properties of a system and may lead to quenching [1, 12-14]. Different ways to account for these heat losses in the system such as preheating the mixture, insulating the wall, etc. used in the previous works will be discussed in the literature review section, Sec. 3. Additionally, the residence time is very small in micro-combustion as it also depends on the size of the domain and it causes incomplete reactions and leads to higher emissions. 
In microscale and mesoscale combustors, thermal instability, the stabilizing and destabilizing effects of flame stretch and heat losses on the wall, respectively, make the theoretical analysis even more difficult [15]. Further, conducting detailed experiments at various operating conditions can provide significant insights into a better understanding of micro-scale combustion. However, it is challenging to conduct such experiments due to constraints in size, measurement techniques, and expenses (materials and time), which stimulates researchers to rely on computational approaches as well, having their limitations in computational costs (memory and time) and thus requiring further simplifications and assumptions applicable to the problem of interest.

\subsection{Syngas combustion}

Fossil fuels have been used in power generation systems due to their high energy densities [16, 17]. However, the concerning impacts of fossil combustion on the climate and environment are frequently questioned. Further, the limiting energy supply calls for a sustainable fuel source. Considering these problems, various alternative fuels have been considered [18]. Synthetic gas (syngas) has been considered as one of the exemplary alternative fuels, due to its low emission rate and sustainability. Syngas, also known as producer gas (before refining) mainly comprises of hydrogen $\left(\mathrm{H}_{2}\right)$, carbon monoxide $(\mathrm{CO})$ and methane $\left(\mathrm{CH}_{4}\right)$ at various proportions.

\subsubsection{Production of syngas}

Syngas can be produced from numerous materials containing carbon such as biomass (wood gas), plastics, coal, municipal waste, etc. It can be bio-derived or coal-based depending on applications and based on clean power generation. Syngas is mostly produced through gasification of carbon contained in such materials as coal, combustible biomass, etc. [17]. These materials, along with oxygen $\left(\mathrm{O}_{2}\right)$ and $\mathrm{H}_{2} \mathrm{O}$ (steam), are fed into a gasifier sketched in Fig. 1.2. With this mixture at high temperatures $\left(800-1000^{\circ} \mathrm{C}\right)$ and pressures $(1-20 \mathrm{bar})$ in the gasifier, numerous chemical reactions occur, which is summarized as

$$
\mathrm{CaHbOcNd}+\mathrm{O}_{2} / \mathrm{H}_{2} \mathrm{O} / \mathrm{N}_{2} \rightarrow \mathrm{CO}+\mathrm{H}_{2}+\mathrm{CO}_{2}+\mathrm{H}_{2} \mathrm{O}+\mathrm{C}_{\mathrm{x}} \mathrm{H}_{\mathrm{y}} \mathrm{O}_{\mathrm{z}}+\mathrm{NH}_{3}+\mathrm{N}_{2} \text {. }
$$




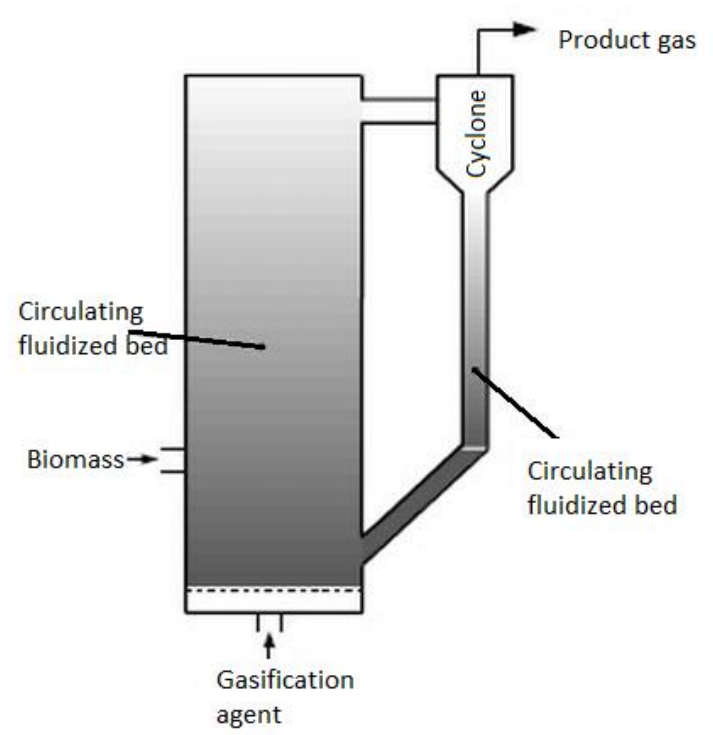

Fig. 1.2: Production of syngas through gasification [17].

Alternative methods have been introduced for syngas production beside this gasification method. Biomass gasification using a catalyst is one of the methods to produce syngas, which works on complete catalytic decomposition of hydrocarbon and does not require heat addition in the system, with $99 \%$ conversion rates and no char accumulation. Further, this method has been proven to reduce the production time by a factor of $10^{1} \sim 10^{2}$ as compared to the conventional integrated coal gasification method [19]. Other methods for syngas production include decomposing $\mathrm{CH}_{4}$ and $\mathrm{CO}_{2}$ using various methodologies such as imposing external factors: micro-wave energy, solar energy, wind energy, electrolysis, etc. to decompose various gases to get the syngas composition.

\subsubsection{Effects of composition on syngas combustion}

Depending upon the production technology, the syngas composition varies as summarized in Table 1.1. Due to this varying composition, syngas has acquired diverse applications. In particular, the higher percentage of $\mathrm{H}_{2}$ aids the syngas to have a high energy density, which is very important in portable power devices for reducing weight and easy maneuverability, hence making this fuel more suitable in the micro-scale combustion applications. The presence of $\mathrm{H}_{2}$ and $\mathrm{CO}$ has helped syngas mixture to exhibit high adiabatic flame temperatures. The laminar burning velocity of premixed syngas combustion grows with the $\mathrm{CO}$ fraction [20]. Furthermore, the flammability limits of $\mathrm{H}_{2}$ in the air are: 4\% (lean limit) for upward propagation and 75\% (at the rich limit) for propagation in both directions; while those for $\mathrm{CO}$ are $12.5 \%$ (lean) and 74\% (rich). This combination of CO and 
$\mathrm{H}_{2}$ provides lower flammability limit than $\mathrm{CH}_{4}$ and higher upper limit than other hydrocarbons as well, providing the higher flammability range than the conventional fuels such as oil or natural gas [21]. Thus, these components exhibit the flame-retardant characteristics while the presence of inert gases, such as nitrogen $\left(\mathrm{N}_{2}\right)$ and carbon-dioxide $\left(\mathrm{CO}_{2}\right)$ reduces the flammability limits of syngas. Further, the composition also affects the emission from syngas burning which is discussed in detail in the literature overview section, Sec. 2.1.

Table 1.1: Syngas composition of different feedstock and gasifiers [22].

\begin{tabular}{ccccccccc}
\multirow{2}{*}{ Feedstock } & $\begin{array}{c}\text { Gasifying } \\
\text { Agent }\end{array}$ & \multicolumn{7}{c}{ Syngas composition( \% mole) } \\
\hline \multirow{2}{*}{ Indian coal } & & $\mathrm{H}_{2}$ & $\mathrm{CO}$ & $\mathrm{CO}_{2}$ & $\mathrm{H}_{2} \mathrm{O}$ & $\mathrm{CH}_{4}$ & $\mathrm{~N}_{2}$ & $\mathrm{CV}(\mathrm{MJ} / \mathrm{kg})$ \\
\cline { 2 - 9 } & Air & 8.8 & 41.8 & 0.623 & 0.018 & 17.3 & 32 & 12.59 \\
\hline \multirow{2}{*}{ Rice Husk } & Oxygen & 15.3 & 60.1 & 0.003 & 0.492 & 0.23 & 0.8 & 19.55 \\
\cline { 2 - 9 } & Air & 22.9 & 18.4 & 13.0 & 8.3 & 0.8 & 36.6 & 5.49 \\
\hline \multirow{2}{*}{$\begin{array}{c}\text { Oxygen } \\
\text { pellets }\end{array}$} & Air & 36.5 & 21.8 & 20.2 & 19.9 & 0.6 & 0.4 & 9.14 \\
\cline { 2 - 9 } & Oxygen & 4.07 & 37.8 & 11.3 & 8.1 & 1.7 & 0.9 & 13.19
\end{tabular}

\subsubsection{Advantages of syngas combustion}

In addition to lower emissions, syngas combustion has numerous extra advantages as compared to conventional fuels. As mentioned earlier, the syngas production methods such as biomass- or coalbased gasification give the opportunity to use biomass feedstocks thereby employing waste management and utilization to energy generation which never eradicates to provide independent power supplies, thereby being very sustainable. Syngas has high thermal efficiency and energy density, and since the rural areas have high access to feedstock, this can help to induce sustainable development in these areas. Syngas production can also be another way of mitigating $\mathrm{CO}_{2}$ emission, being a bonus towards a clean environment by restraining the $\mathrm{CO}_{2}$ concentration in the atmosphere. The syngas fuel production (tri-reforming process [23]) and combustion comprise of two greenhouse gases, $\mathrm{CH}_{4}$ and $\mathrm{CO}_{2}$, further facilitating clean environments. Syngas combustion requires low gas pressure, lower energy cost and higher stability of the system.

\section{Advantages of microscale combustion of syngas mixture}

Microscale combustion has various advantages such as reduction of the ignition time at proper conditions due to lower residence time. The working temperature in the microscale system is 
usually low, especially, during the extinction period. Since the temperature during combustion lies in the lower range the NOx emission is reduced significantly.

\subsubsection{Challenges in syngas combustion}

Due to varying composition during its production, syngas combustion has its advantages, however, it can be a complicated process depending on the feedstock fed and the gasification agent as its composition is highly dependent on the feedstock for gasifiers. The presence of tars, moisture and the post-production level of $\mathrm{H}_{2}$ need to be considered during the refining process of the producer gas. Although various measures have been established during production, preparation of feedstock and post-production refining of the gas to a desirable form is still a hassle such that novel, effective measures are required for the more productive outcomes. In particular, the presence of $\mathrm{H}_{2}$ leading to faster combustion causes pre-ignition, knocking and engine backfiring, thereby demanding for modification of the operating system and thereby extra expenses. Wei et al. [24] conducted a cost analysis on syngas production and identified the operating costs to be the major issue for syngas due to a large labor cost. However, these costs diminish significantly for unit cost if industrialized with improved manufacturing and optimization techniques and if used in higher capacities.

\subsection{Thesis overview}

This thesis covers two different studies with two different changing parameters of the system to analyze and scrutinize their effect on the characteristics of a microscale syngas system and the combustion dynamics. Namely, (i) varying inlet velocities and (ii) varying syngas compositions are considered within the frame of the systematic parametric study. The major focus of this thesis is on the flame dynamics and various ignition, extinction and stabilization properties as well as the features of the flames with repetitive ignition extinction (FRIE). The rest of the thesis is organized as follows. Sec. 2 presents the review of similar works conducted in the past, categorized as the studies of emission, and that of hydrogen-air, methane-air, propane-air and, finally, syngas-air. Sec. 3 discusses the simulation domain, chemical and numerical models and the metrics used in this work. Section 4 is divided into two subsections, where the first one investigates the impacts of varying inlet velocity at a certain mixture composition. Here, the ignition process parameters are defined for two different types of flame defined on the basis of flame stability. In the second part of Sec. 4, the mixture composition is varied, with the analysis of few simulations run at several 
velocities. Finally, the effects of varying inlet velocity and the composition effect are characterized and then followed by the conclusion, recommendations and future work in Sec. 5. 


\section{Literature review}

The high energy density of hydrogen in syngas combustion plays a very important factor in reducing the weight and increasing the production efficiency of the system as compared to the battery-powered systems. The lower emission rate and sustainability of syngas as discussed above further add up to the perks of using syngas in microscale combustion. However, with various constituents having various burning characteristics at a small scale, syngas combustion at micro scales can be more complicated, which needs extra research. Though not enough research has been conducted particularly in microscale syngas combustion, significant information can be gathered from the past results.

\subsection{Emissions in syngas fuel}

Syngas combustion products consist of very low $\mathrm{CO}$ and $\mathrm{CO}_{2}$ gas as compared to conventional fuels. Composition on the syngas can be varied to enhance the emission characteristics, with leanpremixed syngas combustion being close to being emission-free. Whitty et al. [25] have discussed syngas combustion emissions in detail. NOx production in syngas combustion varies with the syngas mixture composition. Specifically, the $\mathrm{H}_{2}$ and $\mathrm{CO}$ components promote the combustion temperature, consequently easing the thermal formation of $\mathrm{NO}$ and $\mathrm{NO}_{2}$. Hydrogen sulfide $\left(\mathrm{H}_{2} \mathrm{~S}\right)$ is not emitted during syngas combustion due to its high reactivity with oxygen, but the trace amount of $\mathrm{SO}_{3}$ and $\mathrm{SO}_{2}$ is present, which depends on the boiler, burner performance and mixing of the gas. $\mathrm{CO}$ is emitted from the exhaust of syngas combustion due to incomplete burning of the hydrocarbon species. The increased flammability range due to higher percentages of $\mathrm{H}_{2}$ and $\mathrm{CO}$ widen the operational range, which reduces the unburnt eddies of improper mixing and assists oxidizing other fuel fractions with increased temperature, which helps in reducing the unburnt $\mathrm{CO}$ or $\mathrm{CO}_{2}$ presence due to incomplete combustion. A syngas-fired boiler is expected to generate volatile organic compounds, which would not exceed $0.5 \mathrm{ppm}$ even in the extreme cases, being much lower than that in the conventional fuels, which can also be reduced with the proper air and syngas mixing. Refined syngas has very little or zero amount of trace elements, such as arsenic, boron, barium, beryllium, calcium, etc. Even though this fuel shows some amount of emissions, very low as compared to the conventional fuel, it is treatable and can be adjusted to produce lower emissions with the proper refinement of syngas during production and adjusting the $\mathrm{CO}$ and $\mathrm{H}_{2}$ fractions as a dominant component to increase mixing. 
Othman et al. [16] demonstrated the effect of the $\mathrm{H}_{2}$ and $\mathrm{CO}$ content on the $\mathrm{NOx}, \mathrm{CO}$ and $\mathrm{CO}_{2}$ emissions and the combustion efficiency in syngas combustion for micro gas turbines. In this work, syngas mixtures of various compositions were burned using a micro gas turbine, where the higher content of $\mathrm{H}_{2}$ and $\mathrm{CO}$ promoted the combustion efficiency; however, the emissions of $\mathrm{CO}$ and NOx were also higher in this case. Fig. 2.1 presents the effect of $\mathrm{H}_{2}$ and $\mathrm{CO}$, by volumetric percentages, on the $\mathrm{CO}$ and NOx emissions.
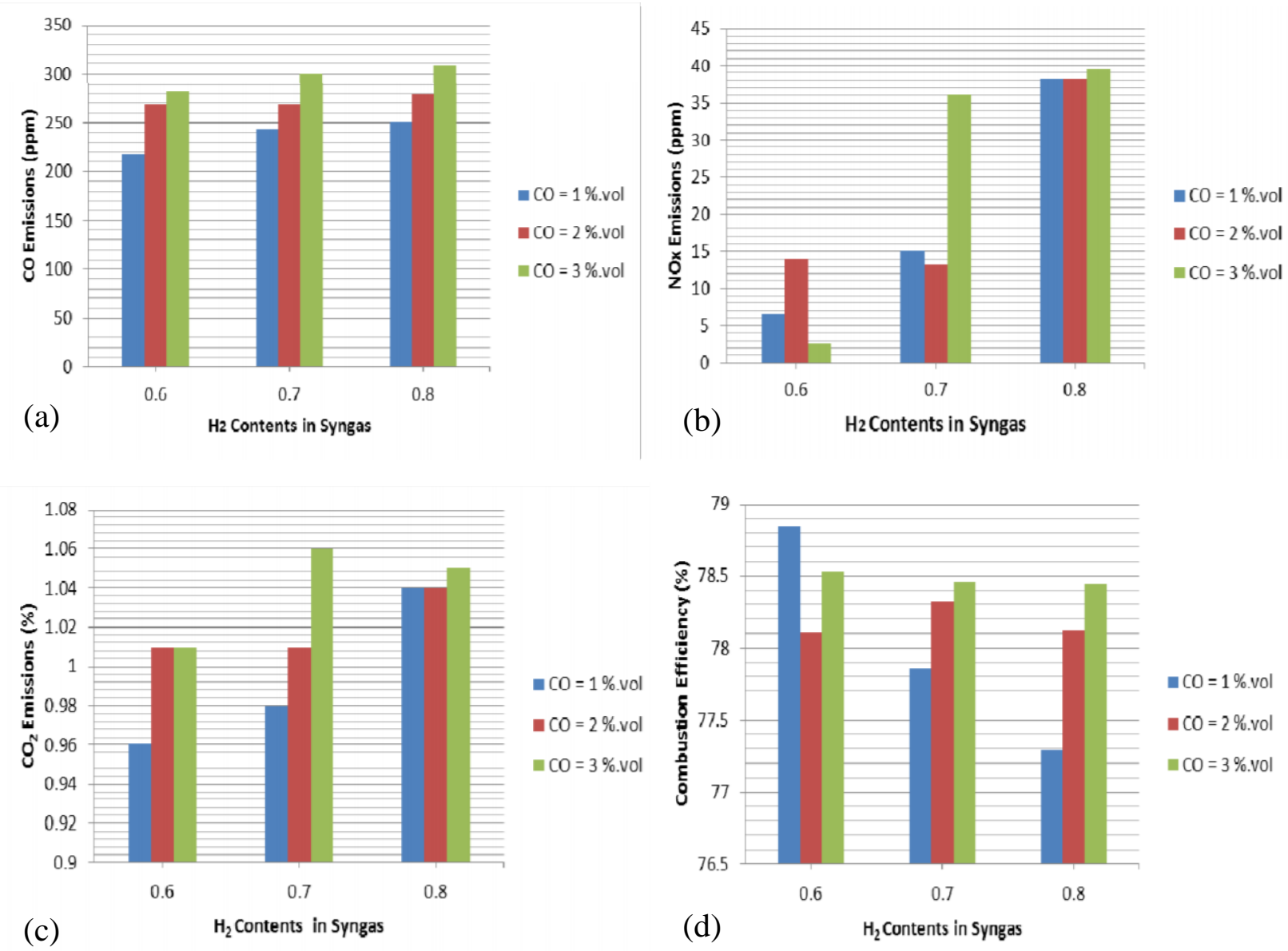

Fig. 2.1: Impact of syngas composition on $\mathrm{CO}(\mathrm{a}), \mathrm{NO}_{\mathrm{x}}(\mathrm{b})$ and $\mathrm{CO}_{2}$ (c) emissions and burning efficiency (d) [16].

\subsection{Combustion study at microscale system for hydrogen/air mixture}

The computational approach to understanding the dynamics of lean $\mathrm{H}_{2}$-air burning was undertaken by Pizza et al. [26] for microscale combustion in channels with varying height (from 0.3 to $1 \mathrm{~mm}$ ) at various uniform inlet velocities (from 1 to $400 \mathrm{~cm} / \mathrm{s}$ ). To account for the convective heat losses through the wall in the system, due to the larger area-to-volume ratio in the microscale combustion system, a fixed temperature profile on the wall has been imposed [26]. From periodic ignition/ 
extinction, symmetric V-shaped flames, and asymmetric flames, to oscillating and pulsating flame - various flame types were observed depending on the height of the channel and the inlet velocity in the case of an $\mathrm{H}_{2}$-air mixture in a microscale system. The results [25] are depicted in Fig. 2.2, where the richest behavior occurs for combustion in the widest channel, and as the inlet velocity grows, the flame transitions to the symmetric front and an asymmetric one with the height increment.

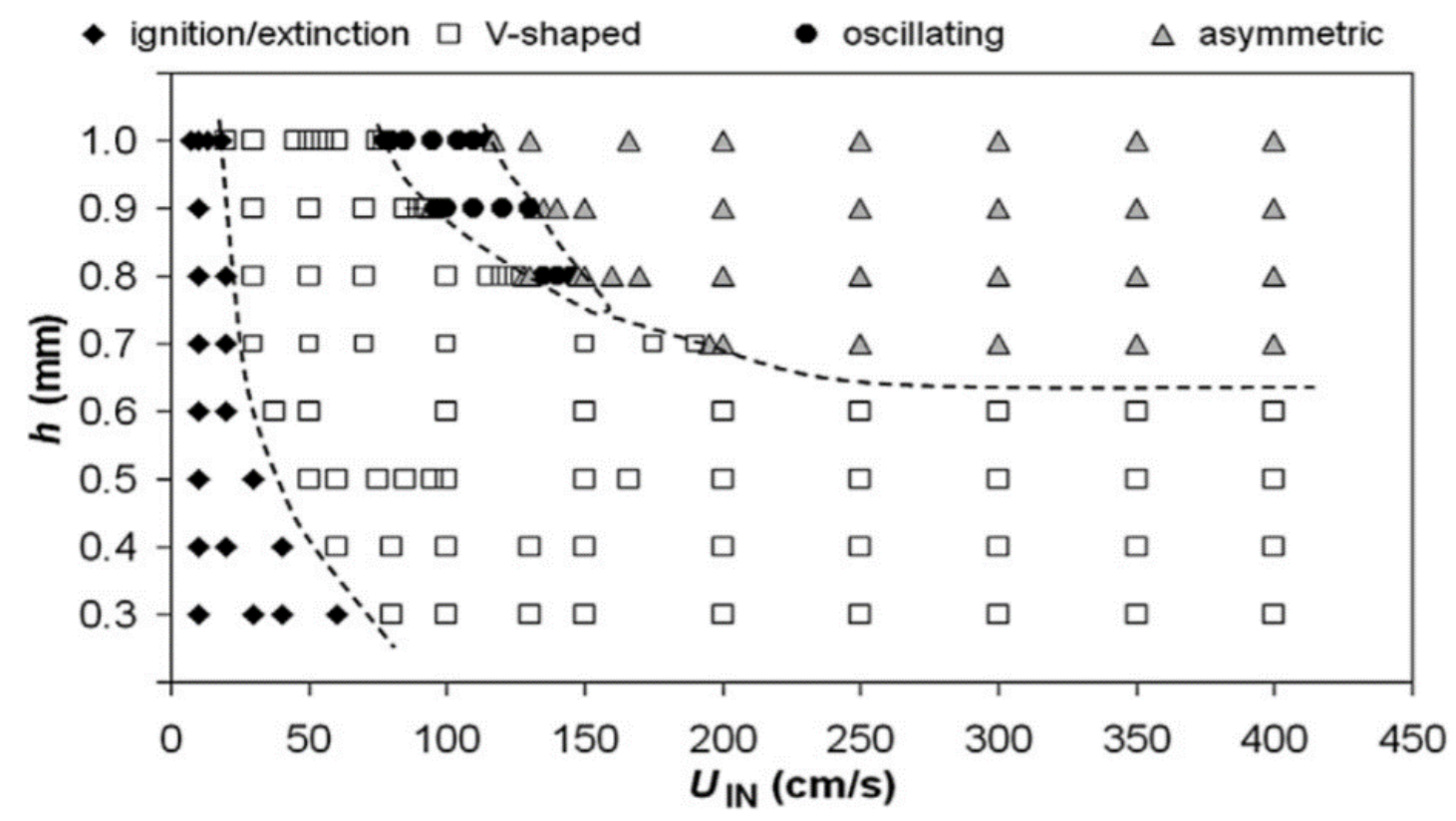

Fig. 2.2: Global stability diagram for microscale premixed combustion for hydrogen-air fuel [26].

\subsection{Combustion study at microscale system for methane/air mixture}

Kim et al. [27] investigated, computationally, premixed $\mathrm{CH}_{4} /$ air combustion in small tubes. The analysis is performed at eight various conditions, with two different thermal boundary conditions (adiabatic and isothermal walls) and four-velocity profiles (three profiles with non-slip and one with slip conditions). In the adiabatic case, the flame propagation velocity is impacted by wall friction, while in the isothermal case the dead space causes local quenching near the wall, which impacts the flame structure and propagation significantly. The flame shape and velocity were found to be dependent on the inlet velocity profile, adiabatic or isothermal wall condition, and the slip or non-slip wall condition.

Similarly, Karagiannidis et al. [28] conducted the numerical analysis of catalytic microreactors (of length and height being 10 and $1 \mathrm{~mm}$, respectively), fueled with a lean $\mathrm{CH}_{4} /$ air mixture, to analyze 
combustion with detailed hetero-homogeneous chemistry at two pressures, of 1 and 5 bar, with various thermal conductivity of the wall, heat transfer coefficient and inlet velocities. For the case of 5 bars, the range of the inlet velocities at which the flame is stable was observed wider than in the case of 1 bar. The role of surface radiation was significant in the unstable system, due to this heat loss, while for the case with limiting inlet velocities, for stable flames, this heat transfer aided stability by transferring heat from the hot to the cold segments of the channel.

Norton et al. [29] studied $\mathrm{CH}_{4}$-air combustion to show the effect of wall thermal conductivity on the flame stability and material integrity of micro-burners. The thermal conductivity of the wall, when low, reduces the upstream heat transfer through the wall which, in turn, decreases preheating of the feed and also results in the hot spots of high temperature on the wall; while high thermal conductivity leads heat transfer area to increase and, hence, it results in extinction. Similarly, the impacts of the flow rate and the wall thickness have been investigated, with the conclusion that a thin wall and a fast flow rate promote the chance for blowout, while a thick wall and a slow flow rate increased the heat transfer area, thereby reducing the probability of the flame stability.

Ayoobi el al. [13] have studied, numerically, the effect of equivalence ratio and channel width on $\mathrm{CH}_{4}$ /air combustion with external wall heating applied. Two asymmetries have been observed depending on the channel height, while the equivalence ratio $(\phi)$ determines whether the limit cycles exhibit a flopping mode or an asymmetric flame with extinction-ignition. Two flame kernels were observed in the wider channel, while only one flame kernel was found in the narrower one.

\subsection{Studies of propane-air combustion in microscale systems}

Several numerical studies of propane-air combustion in a microscale system have been performed in the past. In particular, Munir et al. [30] employed a concentric ring in a cylindrical microchannel to facilitate the flame stability. In this geometry, the wall thermal conductivity was varied to see the roles of various properties of the combustion system, with the effects of inlet velocity and equivalence ratio being analyzed. The increase in both the inlet velocity and the equivalence ratio

promotes the flame temperature thereby increasing the wall and gas temperatures and improving the reaction rate. The blowout limit is reduced when the thermal conductivity is higher [30].

Konakov et al. [31] investigated propane-air combustion in a micro-reactor, employing a threedimensional (3D) numerical model, and then validated the computational results, experimentally, 
with a prototype. The propane $\left(\mathrm{C}_{3} \mathrm{H}_{8}\right)$ mass flow rate was altered to see its effects on the flame. The increase in the $\mathrm{C}_{3} \mathrm{H}_{8}$ mass flow rate promotes the surface area of the flame front, and in the case of non-steady analysis, this facilitates the chances for more stable combustion.

Wang et al. [32] investigated, experimentally and numerically, the effect of scaling on stabilization of $\mathrm{a} \mathrm{C}_{3} \mathrm{H}_{8}$-air flame in a micro-scale porous combustor. Specifically, three various channel heights were considered, with a 3D numerical model established [32]. The flame was observed to be stable, even at a height smaller than the quenching distance, due to increasing heat recirculation from the porous combustor while increasing the risk of extinction. The range of flame stabilization became wider in such a combustor as compared to a non-porous burner. The flame thickness was observed to significantly grow with a decrease in the channel height. The thermal efficiency of these porous combustors was observed to be lower than that of the non-porous combustors.

\subsection{Studies of syngas combustion in microscale systems}

\subsubsection{Experimental study}

Brambilla et al. [33] have also investigated, experimentally and computationally, fuel-lean syngas combustion in mesoscale channels with controlled wall temperature profiles. The work was carried in the channel of $7 \mathrm{~mm}$ height, with equivalence ratios in the range $0.35 \leq \phi \leq 0.42$ and at various volumetric $\mathrm{CO}: \mathrm{H}_{2}$ ratios, from 1:1 to $20: 1$, and with the wall temperatures from 550 to $1320 \mathrm{~K}$. A two-dimensional (2D) numerical analysis included detailed chemistry, while the experiments were performed in a $\mathrm{Si}[\mathrm{SiC}]$ channel with quartz windows for proper visualization, with other required devices such as a thermocouple, an laser-induced fluorescence excitation beam (for $\mathrm{OH}$ monitoring), a coil power (for controlling wall temperatures). The flow was observed to be laminar with the Reynolds numbers up to 500. In this setup, the flow was observed to be mostly stationary at higher wall temperatures and higher $\mathrm{CO}: \mathrm{H}_{2}$ ratios, see the stability map in Fig. 2.3. The numerical model [33] resulted in an asymmetric V-shaped flame in the stationary case, similar to the experimental results, and the oscillation flame properties were almost in the same range, but they appeared very sensitive to the boundary conditions applied. It was also shown that the emissions are higher in oscillatory flames, due to incomplete combustion.

Federici et al. [34] experimentally studied syngas catalytic combustion in a micro-reactor with the main conduit of length $70 \mathrm{~mm}$ and width $10 \mathrm{~mm}$, with $\mathrm{Pt} / \mathrm{Al}_{2} \mathrm{O}_{3}$ used as the catalyst. The mixture 
was preheated, and the thickness of the shell and high conductive wall was used to get the dominant axial heat transfer. This has been measured with thermocouples installed at various locations at the wall. The work [34] shows the impact of the $\mathrm{H}_{2}: \mathrm{CO}$ volumetric ratio on syngas combustion reaction mechanism, with CO's absence, the reaction occurred at room temperature, but when both $\mathrm{H}_{2}$ and $\mathrm{CO}$ are present, the reaction occurred only after significant $\mathrm{CO}$ conversion is gained, which means that $\mathrm{CO}$ is the limiting agent in the reaction. The $\mathrm{CO}$ oxidation was promoted with the amount of addition of $\mathrm{H}_{2}$, and the positive order kinetics of $\mathrm{CO}$ oxidation with respect to $\mathrm{H}_{2}$ was observed when the $\mathrm{H}_{2}$ : $\mathrm{CO}$ volumetric ratio was smaller than unity. But these parameters were unaffected when the fraction of $\mathrm{H}_{2}$ was higher; the $\mathrm{H}_{2}$ : $\mathrm{CO}$ exceeded unity. Though this experiment shed some light on the process, it did not provide combustion characteristics of the system such as the flame shape, ignition time and distance, existence of a stable flame, its time and distance.

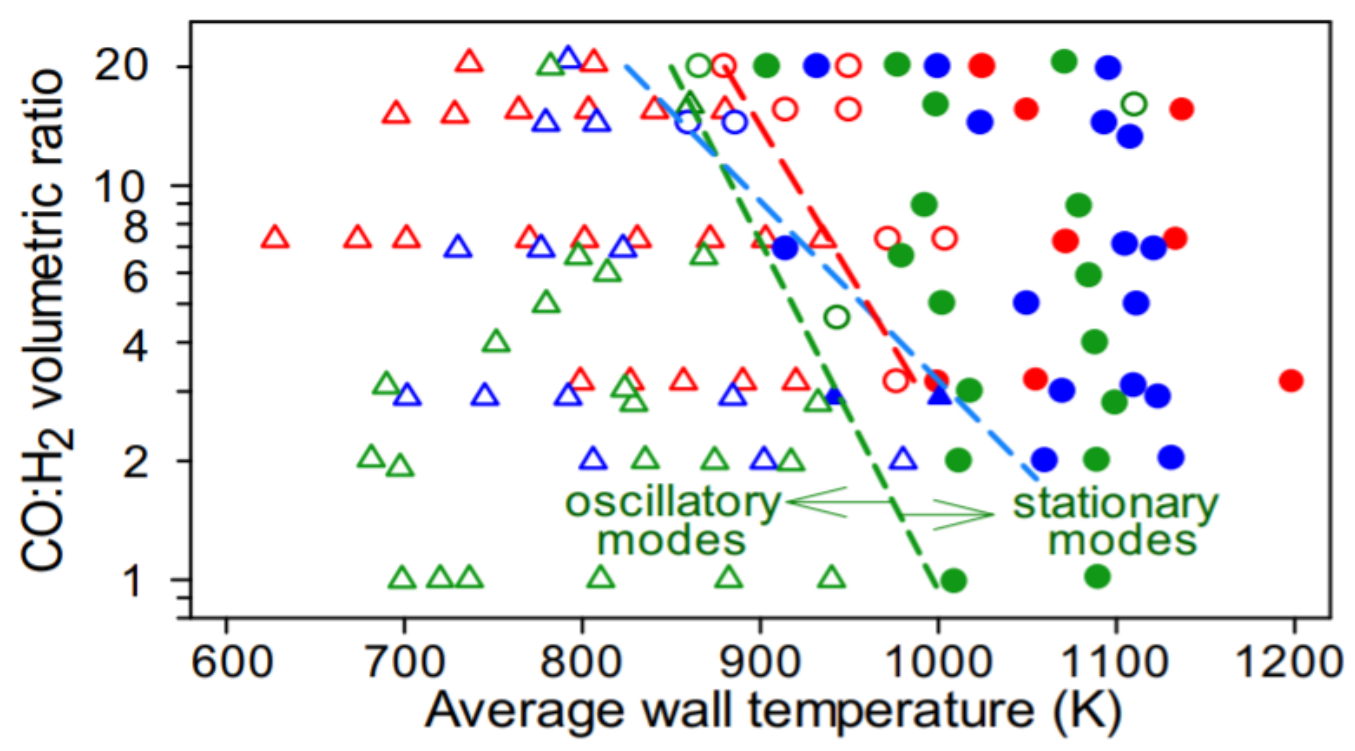

Fig. 2.3: Experimentally deduced stability maps. Circles: stationary modes, triangles: oscillatory modes. Filled symbols: modes with nearly symmetric shapes, open symbols: asymmetric modes. Red symbols: $\phi=0.42$, blue symbols: $\phi=0.30$, green symbols: $\phi=0.25$. Dashed lines demarcate regions of stationary (right) and oscillatory (left) modes, for each investigated $\phi[33]$.

The experimental and computational study of Varghese et al. [20] showed the effects of the CO content on the laminar burning velocities of syngas-air premixed combustion, including its flame dynamics. The rectangular channel of $25 \mathrm{~mm}$ length and $2 \mathrm{~mm}$ width, made of quartz, with low thermal conductivity and high heat capacity was used to visualize the combustion process unlike the stainless steel employed by Othman et al. [16]. External heating was provided to the wall to obtain the axial temperature gradient in the system for flame stabilization and to maintain the 
adiabatic wall condition. The experiment is set-up to obtain the planar flame with all the required instruments such as mass flow controllers, pressure regulator thermocouple, heater, camera, and various mixture compositions are input in a setup at various conditions. The planar flame was observed for the channel aspect ratio of channel 12.5 and diverging angle $10^{\circ}$ with three different mixture composition used: lean $\mathrm{CO}\left(\mathrm{C} 1\right.$ is $15 \% \mathrm{CO}, 15 \% \mathrm{CO}_{2}, 15 \% \mathrm{H}_{2}$ and $55 \% \mathrm{~N}_{2} ; \mathrm{C} 2$ is $20 \%$ $\mathrm{CO}, 15 \% \mathrm{CO}_{2}, 15 \% \mathrm{H}_{2}$ and $\left.50 \% \mathrm{~N}_{2}\right)$ and rich $\mathrm{CO}\left(\mathrm{C} 3\right.$ is $25 \% \mathrm{CO}, 15 \% \mathrm{CO}_{2}, 15 \% \mathrm{H}_{2}$ and $45 \%$ $\mathrm{N}_{2}$ ) is presented in Fig. 2.4c. Further, the laminar burning velocities at different temperature ratios (i.e. the mixture temperature to the reference inlet temperature ratio), different compositions at ambient conditions, at different $\mathrm{CO}$ volumetric fractions (lean and rich) at elevated temperature are given in Fig. 2.4. The laminar burning velocity grows with the mixture temperature as well as with the fuel and the $\mathrm{CO}$ contents.
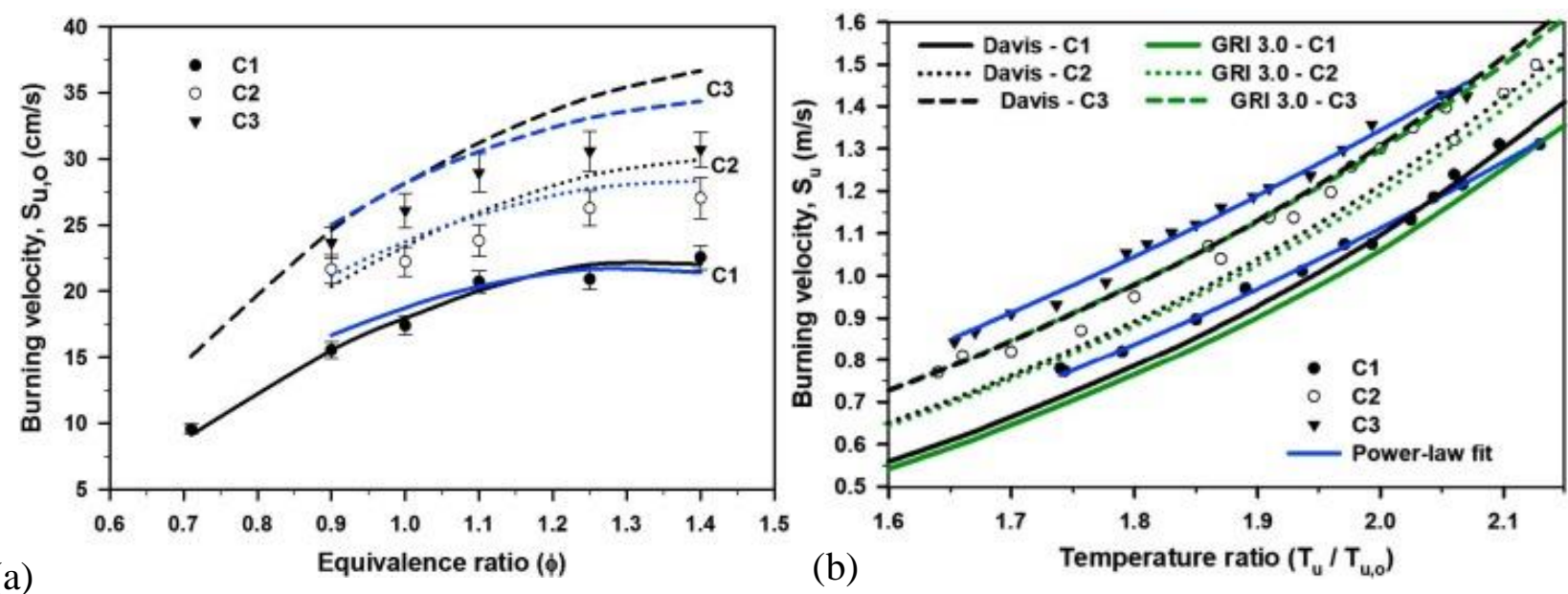

(a)

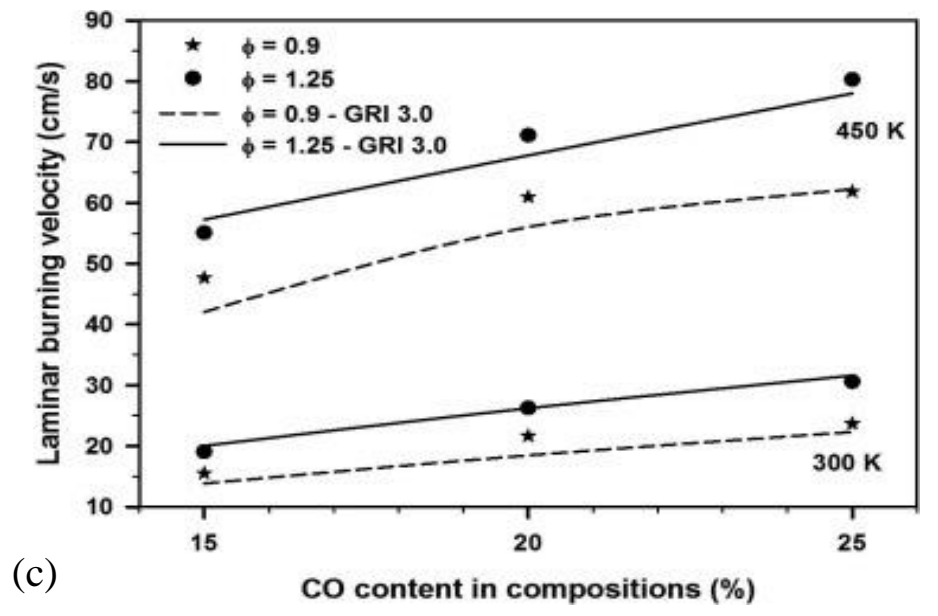

Fig. 2.4: The laminar flame velocity versus the equivalence ratio (a), temperature ratio (b) and CO content (c) [20]. 


\subsubsection{Computational study}

Takbiri-Borujeni et al. [35] analyzed syngas-air micro-combustion in a 2D channel of length 20 $\mathrm{mm}$ and width $2 \mathrm{~mm}$ through numerical simulations with detailed chemical kinetics. The inlet flow was parabolic, and the fixed temperature gradient was imposed on an upper wall for smooth ignition and extinction. The analysis was performed for two compositions (Mixture 1: 30\% CO, $5 \% \mathrm{CH}_{4}, 65 \% \mathrm{H}_{2}$ and Mixture 2: $40 \% \mathrm{CO}, 10 \% \mathrm{CH}_{4}, 50 \% \mathrm{H}_{2}$ ) of a lean syngas.

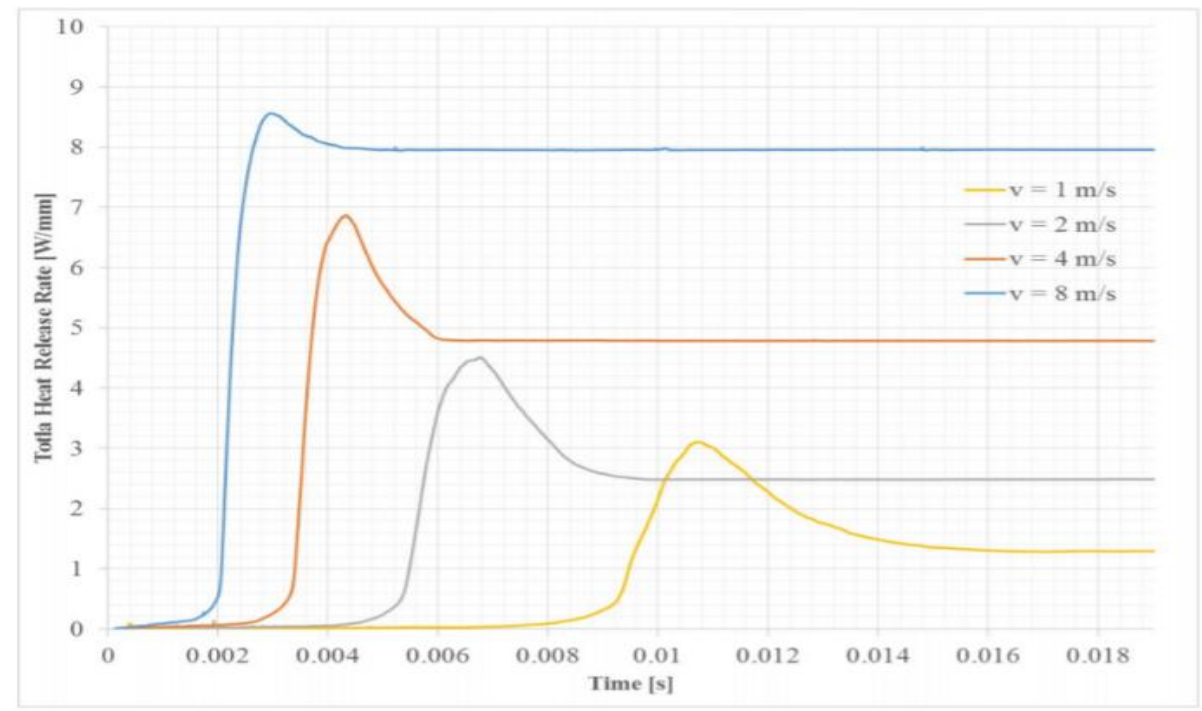

(a)

Fuel Mixture 1

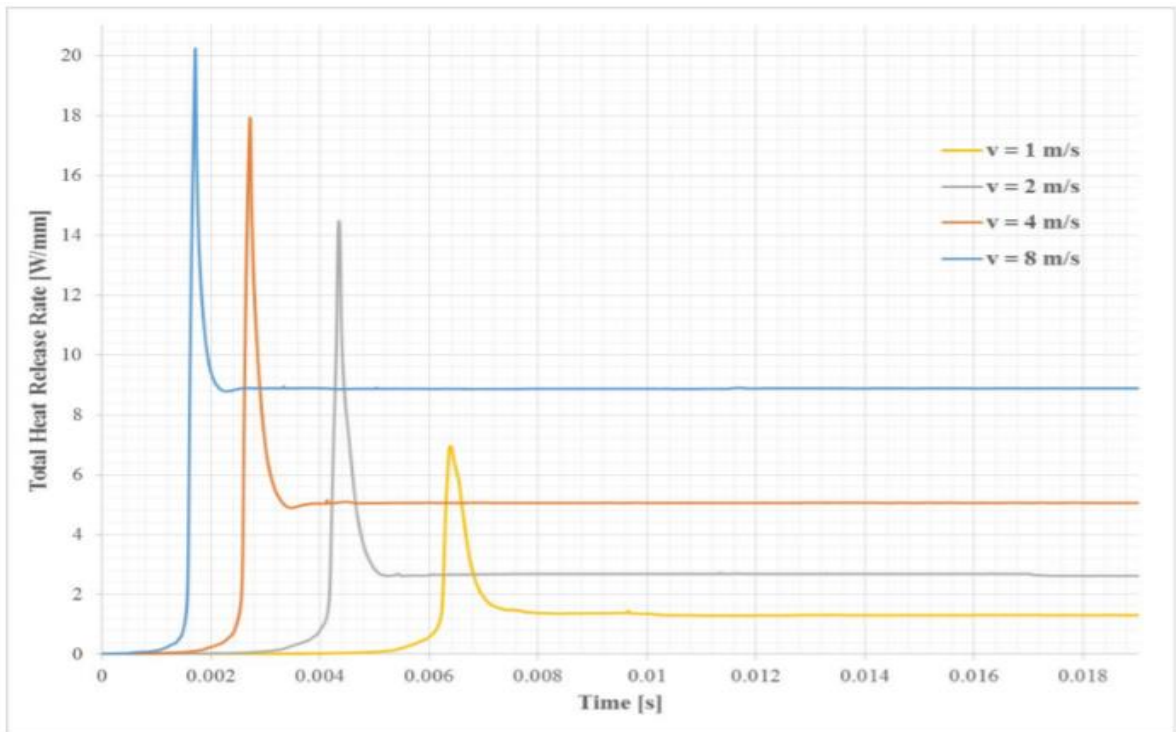

(b)

\section{Fuel Mixture 2}

Fig. 2.5 : (a) Time variant total heat release rate in the domain against simulation time. It is noted that in addition to cases 1-1 and 2-4, this figure includes 3 more inlet velocities for each mixture for the sake of comparison and to indicate the importance of inlet velocity on the flames behavior [35]. 
Four different velocities are considered, and Fig. 2.5 shows the dependence of the ignition time versus the inlet velocity. The stable $\mathrm{V}$-shaped flames have been observed. The larger inlet velocity showed a more stretched flame as it experienced a larger area to burn the fuel.

As justified in this section, the microscale combustion research conducted so far is still not enough, especially considering syngas combustion. It is evident that microscale combustion provides more efficient and optimized results in terms of most important parameters of premixed syngas, but such a system and a process require much more scrutinized work to get the maximum possible outcome. Thus, the present thesis focuses on syngas combustion in a microscale system to understand more about its various combustion properties and flame stability and its dependence on various other parameters. 


\section{Methodology}

Due to the complexity and tediousness of experiments because of constraints in size, measurement techniques, material cost and time expenses, computational approaches are also used to analyze the microscale combustion. Thus, my thesis is devoted to a numerical study of syngas microscale combustion, which is done using a commercial fluid solver, ANSYS Fluent [36] - a finite-volumebased computational fluid dynamics (CFD) tool, which is widely employed in both industry and academics to model and optimize fluids, turbulence, heat transfer and reactions in a system under consideration. ANSYS Fluent has various applications such as analyzing these fluid dynamics, heat transfer, a chemical reaction in combustion power plants, various types of turbines, wing blades (airplane to a wind turbine), human circulatory system, etc. As given in Fig. 3.1, there are several steps for performing a numerical analysis with ANSYS Fluent. Preprocessing means making a computational model ready by creating a geometric model and generating mesh before importing it into the ANSYS Fluent solver. The ANSYS Fluent package provides us with advanced modeling capabilities, with robust solvers to handle turbulence, acoustic coupling, reacting flows, multiphase flows, etc. The simulations can be run repetitively, with optimized geometry, to get an efficient outcome. A bunch of user-defined functions (UDF) can be incorporated into the simulations. After a simulation is completed, the results are gathered using post-processing options of ANSYS Fluent.

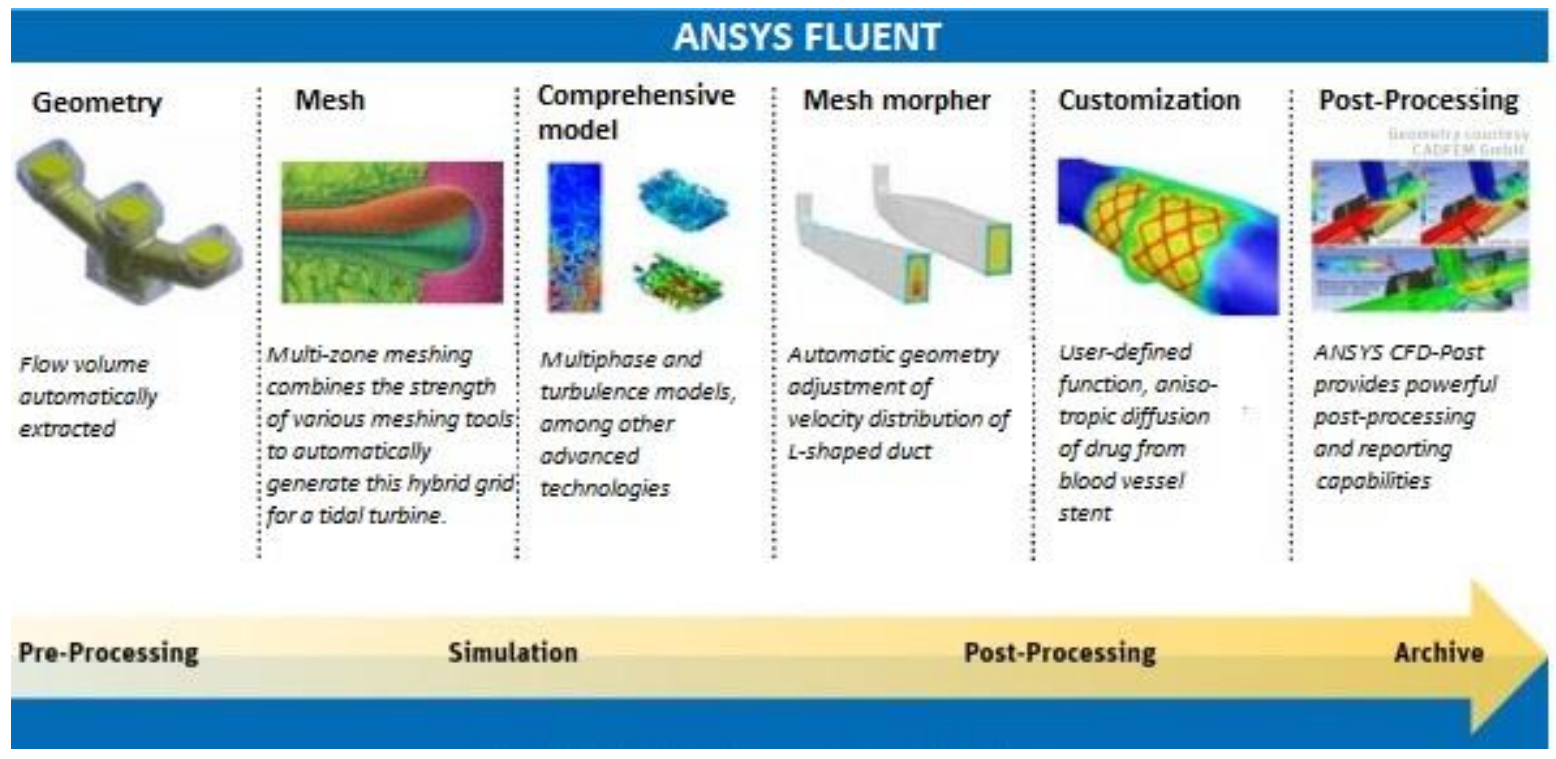

Fig. 3.1: ANSYS Fluent [37]. 


\subsection{Computational domain}

The computational domain is a $2 \mathrm{D}$ or a $3 \mathrm{D}$ spatial region divided into the discretized elements (mesh) to computationally describe the physics or chemistry of the system under consideration. In this work, the computational domain and the mesh are created using the ANSYS Workbench design and the meshing tool, respectively [36]. For this thesis, the computational domain is simply a 2D channel discretized with a uniform square mesh of size $0.05 \mathrm{~mm}$. The length of the channel is $20 \mathrm{~mm}$ and the width is $2 \mathrm{~mm}$. To reduce the computational costs, only the upper half of the channel is simulated with an axisymmetric condition adopted at the lower domain boundary. Thus, only a half-width $(1 \mathrm{~mm})$ is simulated as shown, schematically in Fig. 3.2. The inlet and the outlet are on the left and right extremes of the channel, respectively, where the fluid flows from the inlet to the outlet, with a given inlet velocity in the axial direction (the $x$-axis).

As discussed in the literature review in Sec. 2, for microscale combustion, due to a large surface area to volume ratio, the wall heat losses are very high, and the energy needed for a self-sustained reaction is not gained unless effective measures are employed. To account for this conjugate heat transfer, a fixed temperature gradient is imposed at an upper boundary of the computational domain such that the wall temperature increases linearly from $300 \mathrm{~K}$ at the inlet to $1500 \mathrm{~K}$ at the outlet. Technically, this is implemented utilizing a user-defined function in ANSYS Fluent. As explained in Sec. 1.2.3, the flow becomes dominantly laminar with the Reynolds numbers being very low in narrow channels. Thus, we do not have turbulence in such a system, so that the species transport model is used here without any turbulence. Other parameters such as the inlet velocity of the fuel mixture, temperature, boundary conditions, time steps, etc. are modeled in ANSYS Fluent after importing the geometry. The inlet mixture flow has a uniform velocity profile with a constant temperature. Non-slip boundary condition is adopted for flow interaction with the wall.

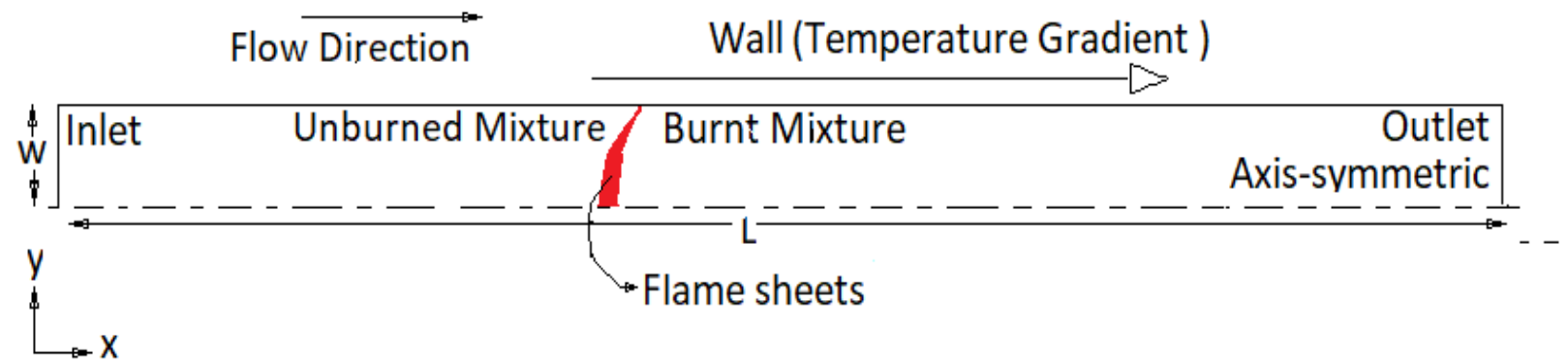

Fig. 3.2: A schematic diagram of the computational domain. 


\subsubsection{Grid resolution}

Finite volume analysis is a numerical methodology, according to which any physical phenomena are simulated by dividing the domain into discretized small volumes and computing the results at each small volume as control volume and combining them using the finite volume method. Thus, these small volumes, also regarded as mesh elements here, play a very important role to accurately mimic the physical phenomena and produces the effective results. The larger the number of mesh elements in the domain (i.e. this discretized volume becomes smaller), the higher the chances of it mimicking the phenomena properly, thereby increasing the accuracy of the results as it employs boundary conditions in more part of the domain. However, this increases the computational time and the file size as it has a larger amount of data to compute. So, the optimum size of the mesh needs to be chosen in order to get accurate results by nevertheless utilizing as minimal resources as possible. The grid resolution test helps us to choose an optimum size of these mesh elements. Since 2D simulations are run here, the mesh is discretized into a square grid. Three simulations are run with different sizes of the square mesh (being $0.02 \mathrm{~mm}, 0.05 \mathrm{~mm}$ and $0.1 \mathrm{~mm}$ ) with all other conditions kept identical. The time evolution of the total heat release rate $\left(H R R_{T}\right)$ is plotted and is given in Fig. 3.3, where we observe that although $H R R_{T}$ experiences some variations, the ignition time, determining most of the combustion parameters, is practically the same for all three meshes. The time to run the simulations increased almost 2 times and the space occupied by the simulation increased almost 3 times as the mesh size was decreased from $0.1 \mathrm{~mm}$ to $0.05 \mathrm{~mm}$ and $0.05 \mathrm{~mm}$ to $0.02 \mathrm{~mm}$. However, the mesh of size $0.02 \mathrm{~mm}$ provides smoother data as compared to the other two meshes. Considering the time to run the simulation and the size of the simulation file, a mesh element size of length $0.05 \mathrm{~mm}$ is chosen.

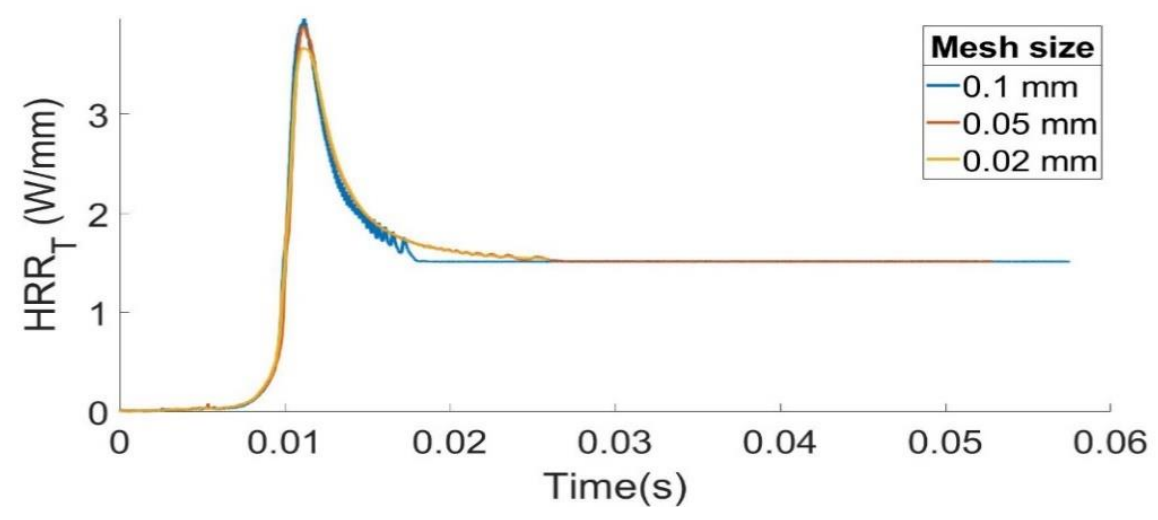

Fig. 3.3: The grid resolution test: A comparison of the cases with various mesh sizes for the inlet velocity of $1 \mathrm{~m} / \mathrm{s}$. 


\subsubsection{Time resolution}

For unsteady flows, the properties of the flow vary with time and this kind of problem is solved at different characteristic time intervals before it reaches the steady flow. So, to gain this condition, the simulations are carried out for some time. In CFD, this time is divided into intervals and the calculations are carried at each of them. Such an interval or an incremental change in time is known as the time step, which should be chosen cautiously as too large time steps might give inaccurate results while smaller time steps make the simulations to be longer with the larger file size. Here, to choose the time step, the simulations are run with various time steps, with all other conditions kept identical. The time evolution of $H R R_{T}$ is plotted in Fig. 3.4. Here, the difference between the peaks of $H R R_{T}$ for the time steps not exceeding $10^{-5} \mathrm{~s}(=10 \mu \mathrm{s})$ is minor as compared to the result with a time step of $50 \mu \mathrm{s}$. Thus, considering also that the real computational time grows more than twice as the time step grows in this range, all simulations are performed with a time step of $10 \mu \mathrm{s}$.

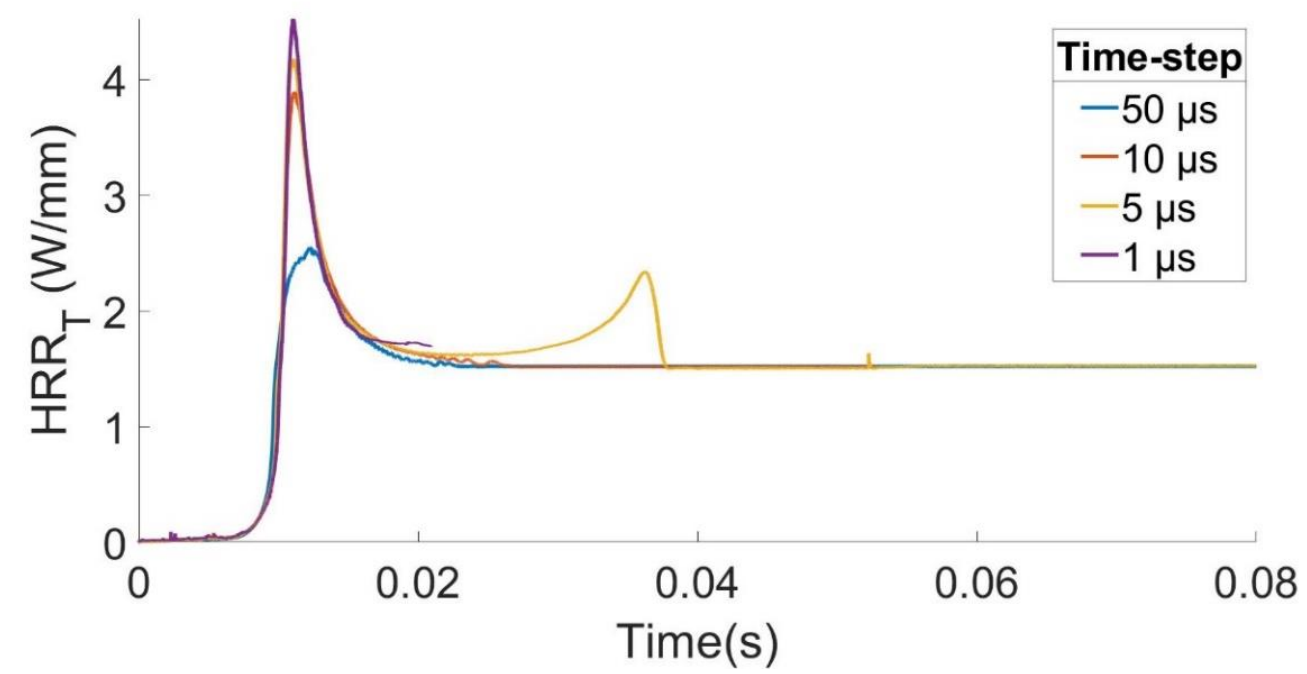

Fig. 3.4: The time resolution test: comparison between the runs at various time steps for the inlet velocity of $1 \mathrm{~m} / \mathrm{s}$.

\subsection{Chemical model}

Chemically, syngas is comprised of numerous gases such as $\mathrm{H}_{2}, \mathrm{CH}_{4}, \mathrm{CO}, \mathrm{CO}_{2}$, and $\mathrm{N}_{2}$, with few traces of other hydrocarbons such as $\mathrm{C}_{2} \mathrm{H}_{6}, \mathrm{C}_{3} \mathrm{H}_{8}$, etc., and inert gases. In my thesis, only the major constituents of syngas are considered, namely, stoichiometric air-fuel burning, with the fuel made of $\mathrm{CO}, \mathrm{CH}_{4}$ and $\mathrm{H}_{2}$, is studied. The chemistry is modeled by the detailed San Diego mechanism comprising 46 species and 235 reactions [38]. This mechanism is imported in ANSYS Fluent with the help of the Chemkin package. 
The composition of the fuel-air mixture is imported as the boundary condition at the inlet in terms of the inlet mass fractions for various components, each of them obtained from a global mechanism

$$
\mathrm{xCH}_{4}+\mathrm{yCO}+\mathrm{zH}_{2}+\mathrm{a}\left(\mathrm{O}_{2}+3.76 \mathrm{~N}_{2}\right) \rightarrow \mathrm{bCO}_{2}+\mathrm{cH}_{2} \mathrm{O}+\mathrm{dN}_{2} \text {, }
$$

where

$$
\begin{aligned}
& a=\frac{4 x+y+z}{2}, \\
& b=x+y, \\
& c=2 x+z, \\
& d=3.76\left(\frac{4 x+y+z}{2}\right) .
\end{aligned}
$$

Table 3.1: Syngas mixture compositions studied in this work

\begin{tabular}{|c|c|c|c|}
\hline Case & $x(\%)$ & $y(\%)$ & $z(\%)$ \\
\hline A & 30 & 5 & 65 \\
\hline B & 70 & 5 & 25 \\
\hline C & 60 & 10 & 30 \\
\hline
\end{tabular}

Here $x, y$ and $z$ are the percentage mass fraction of $\mathrm{CH}_{4}, \mathrm{CO}$ and $\mathrm{H}_{2}$, respectively with the help of which other parameters (a, b, c, d) are calculated in the global equation, Eq. (3.1). These fractions of $\mathrm{CH}_{4}, \mathrm{CO}$ and $\mathrm{H}_{2}$ are varied according to Table 3.1, and the results are described in Sec. 4.2. The composition is chosen in such a manner that for composition $\mathrm{A}$, a common distribution of $\mathrm{CH}_{4}$, $\mathrm{CO}$ and $\mathrm{H}_{2}$ for syngas composition is maintained. Compositions $\mathrm{B}$ and $\mathrm{C}$ are chosen in such a way that the $\mathrm{H}_{2}$ fraction is reduced almost twice and the $\mathrm{CH}_{4}$ fraction doubles keeping the $\mathrm{CO}$ fraction the same for composition B, and doubling it for composition $\mathrm{C}$.

\subsection{Numerical model}

The simulations are performed on ANSYS Fluent without including any kind of turbulence. Thus, the governing numerical equations used in this simulation to solve the problems are basic conservation law which is described below:

\section{Conservation of mass}

The law of mass conservation states that the mass can neither be created nor destroyed. In our case, the mass provided in the system should balance that coming out of the system; in other words, the mass of reactant in the chemical reaction should be equal to that of products. This is described by

$$
\frac{\partial \rho}{\partial t}+\nabla \cdot(\rho \vec{v})=S_{m}
$$


which is valid for compressible as well as incompressible flows. The first term is the rate of gain of mass per unit volume and the second term is the net rate of mass flow out of the system. The source $S_{m}$ is the mass added to the continuous phase from the second phase if present which is zero in this case. The quantities $\rho$ and $\vec{v}$ are the density and flow velocity in the system.

\section{Conservation of momentum}

The principle conservation of momentum states that within a system, the momentum which is the product of mass and velocity of the object always remains constant unless an external force is applied to or from the system. It is given by

$$
\frac{\partial}{\partial t}(\rho \vec{v})+\nabla \cdot(\rho \vec{v} \vec{v})=-\nabla p+\nabla \cdot(\overline{\bar{\tau}})+\rho \vec{g}+\vec{F}
$$

Here, the first and the second terms are the rates of change of momentum within the system and momentum influx into the system which equals the summation of forces acting into the system that is the right-hand side of the equation. Here, $p$ is the static pressure, $\rho$, and $g$ and $\overrightarrow{\mathrm{F}}$ are the gravitational body force and external body forces, respectively.

\section{Conservation of species}

The general species conservation used during the computations is described by the equation

$$
\frac{\partial}{\partial t}\left(\rho Y_{i}\right)+\nabla \cdot\left(\rho \vec{v} Y_{i}\right)=-\nabla \cdot \overrightarrow{J_{l}}+R_{i}+S_{i}
$$

In this equation, the first term denotes the rate of gain of the mass of species ' $i$ ', per unit volume, the second term gives the net rate of mass flow of ' $i$ ' species out by diffusion and the bulk flow per unit volume. The right-hand side term is the net rate of mass production of species ' $i$ ' per unit volume. Here, $R_{i}$ is the net rate of production of species ' $i$ ' in a chemical reaction and $S_{i}$ is the rate of creation by addition from the dispersed phase plus any user-defined sources, which is zero in this computation. The local mass fraction of each species, $Y_{i}$, is predicted by solving a convectiondiffusion equation for the $i^{t h}$ species.

\section{Conservation of energy}

Conservation of energy means that the total energy of a system cannot be destroyed or created in the system. At the same time, the energy inside the system may change from one form to another such as in hydropower, potential energy to mechanical energy, in combustion, chemical energy to thermal or mechanical energy, etc. In our case, the conservation of energy reads

$$
\rho C_{p} \frac{\partial T}{\partial t}+\rho C_{p} v \nabla T=-\nabla q-\rho \sum_{i=1}^{N} C_{p, i} Y_{i} V_{i}-\sum_{i=1}^{N} h_{i} \Omega_{i}
$$


where $C_{p}$ is the specific heat at constant pressure, $T$ the temperature, $V_{i}, h_{i}$ and $\Omega_{i}$ the diffusion velocity, enthalpy and the net rate of production of $i^{\text {th }}$ species, $i=1 \ldots \mathrm{N}$.

\subsection{Metrics used in this work}

Simulations are post-processed, and the results are analyzed and described in Sec. 4 with various metrics explained below.

\subsubsection{Heat release rate}

The heat release rate (HRR) is the heat energy released in the combustion system. In an exothermic reaction, the heat released from all the reactions at the local point or, in our case, in a computational cell is known as the heat release rate. It is a local property, which is obtained from the summation of net heat release of all reactions involved at each computational cell as follows:

$$
H R R=\sum_{n} \dot{h}_{r},
$$

where $\dot{h_{r}}$ is the heat released from a reaction, and $n$ is the total number of the reactions in a cell.

\subsubsection{Total heat release rate}

The total heat release rate $\left(H R R_{T}\right)$ describes the state of the system at a certain time for unsteady simulations, since it shows the energy released from the whole domain. The total heat release rate is calculated by integrating/summarizing the local $H R R$ over the computational domain, namely:

$$
H R R_{T}=\sum_{m} H R R=\sum_{m} \sum_{n} \dot{h_{r}},
$$

where $m$ is the total number of discretized elements in the domain. The $H R R_{T}$ of the system in this study will determine most of the combustion properties such as ignition, stabilization, FRIE time.

\subsubsection{Ignition time}

In this exothermic reaction, after certain time autoignition occurs in the system. The time at which it occurs is defined here as the ignition time $\left(t_{i g}\right)$. During autoignition, the energy of the system rises in a very rapid manner which can be observed in the $H R R_{T}$ versus time graph. Thus, ignition time is described as the time at which $H R R_{T}$ reaches its peak value before stabilization occurs, i.e.

$$
t_{i g}=t_{\left(H R R_{T}\right)_{\max }} .
$$




\subsubsection{Extinction time}

In microscale combustion, when energy released from a reaction is not enough for self-sustained propagation, a flame, established at the time of ignition, eventually extinguishes. At this stage, the energy of the system is zero which can also be found from the $H R R_{T}$ versus time plot. Thus, the extinction time $\left(t_{e x}\right)$ is described as the time at which the $H R R_{T}$ becomes zero,

$$
t_{i g}=t_{\left(H R R_{T}=0\right)} \text {. }
$$

In this work, this occurs in the case with lower velocity, where we observe the FRIE phenomenon.

\subsubsection{Ignition and stable flame:}

After ignition occurs, the flame front is generated, propagating from the burnt product towards the unburnt mixture, and then stops reaching the stable state where chemical equilibrium is obtained. The flame generated at the time of ignition or right after the ignition starts is defined as an ignition flame. Similarly, the flame after the combustion stabilizes is defined as a stable flame.

(a)

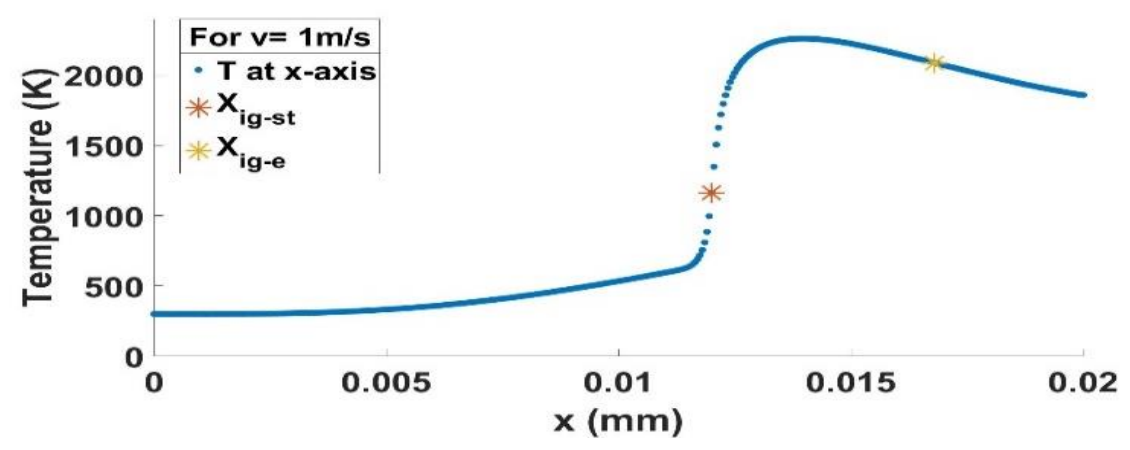

(b)

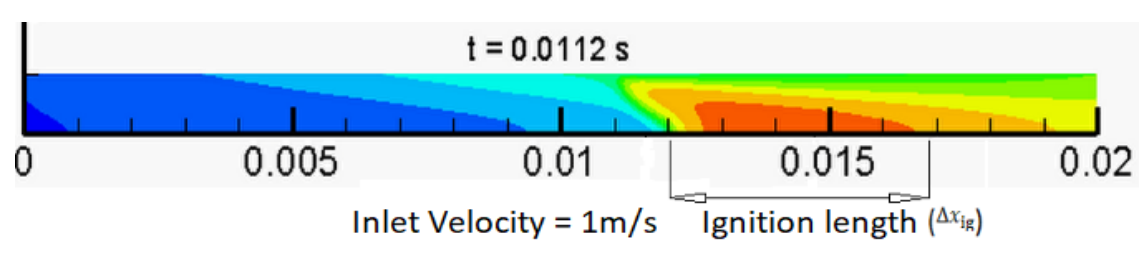

Fig. 3.5: The temperature distribution along the $x$-axis (a) and the temperature color snapshot (b) at the time of ignition for the inlet flow velocity of $1 \mathrm{~m} / \mathrm{s}$.

\subsubsection{Ignition location and length}

The ignition location is defined as a range of points, where the ignition starts and stops, and the ignition length is the span of this range or the length of the ignition in the axial direction. Here, the ignition location/length is based on the temperature distribution at the ignition time. This is done by extracting the temperature distribution over the axis of the domain at $t_{i g}$. From this plot, the 
ignition location is defined as that where the ignition flame starting point, $x_{i g-s t}$, is the point at the axial location at which positive temperature gradient peaks,

$$
x_{i g-s t}=\left(x_{\left(\frac{d T}{d x}\right)_{\max }}\right)_{i g},
$$

and the ignition flame ending point, $x_{i g-e}$, is the point at the axial location at which the negative temperature gradient peaks,

$$
x_{i g-e}=\left(x_{\left(\frac{d T}{d x}\right)_{\min }}\right)_{i g} .
$$

Accordingly, such a distance between these two points represents an indication of ignition length which is the difference between the ignition flame starting and stopping point at the ignition time,

$$
\Delta x_{i g}=x_{i g-s t}-x_{i g-e}
$$

Figure 3.5a shows the temperature distribution in axis for the case A with the inlet velocity of 1 $\mathrm{m} / \mathrm{s}$, where the positive and negative slopes are observed, providing $x_{i g-s t}, x_{i g-e}$ and $\Delta x_{\text {ig. }}$. Figure $3.5 \mathrm{~b}$ presents the corresponding point at the time of ignition in the $2 \mathrm{D}$ channel for this case.

\subsubsection{Stabilization location and length}

In premixed combustion, after a flame is ignited, it propagates from the burnt matter/combustion residual side to the unburnt fuel mixture side. After some time, a state is seen where the flame stops propagating, and it becomes stationary and self-sustainable until the fuel mixture is provided. Thus, the stabilization location and length are, respectively, the location and length of such a stable and stationary flame. Specifically, the stabilization location is the range of points after the stable flame starts and stops, and the stabilization length is the span of this range or the length of the stable flame in the axial direction. Similar to the ignition location, the stabilization location is also defined using the axial temperature distribution over the axis at the domain, when the flame has been stabilized. Hence, from this plot, the stabilization location is defined where the stable flame starting point, $x_{s z-s t}$, is the point in the axial location at which positive temperature gradient peaks,

$$
x_{s Z-s t}=\left(x_{\left(\frac{d T}{d x}\right)_{\max }}\right)_{s z},
$$

and the stable flame ending point, $x_{s z-e}$, is the point at the axial location at which the negative temperature gradient peaks, 


$$
x_{S Z-e}=\left(x_{\left(\frac{d T}{d x}\right)_{\min }}\right)_{S Z} .
$$

Accordingly, the distance between the two points represents an indication of stabilization,

$$
\Delta \mathrm{x}_{\mathrm{Sz}}=\mathrm{x}_{\mathrm{Sz}-\mathrm{st}}-\mathrm{x}_{\mathrm{Sz}-\mathrm{e}} \text {. }
$$

Figure 3.6a shows the temperature distribution in the axis for the case A with the inlet velocity of $1 \mathrm{~m} / \mathrm{s}$, where positive and negative slopes give the $\mathrm{x}_{\mathrm{Sz}-\mathrm{st}}$ and $\mathrm{x}_{\mathrm{sz}-\mathrm{e}}$. Finally, the $\Delta \mathrm{x}_{\mathrm{sz}}$ is related point in 2D channel at the time of ignition is shown in Fig. 3.6-b for this case.

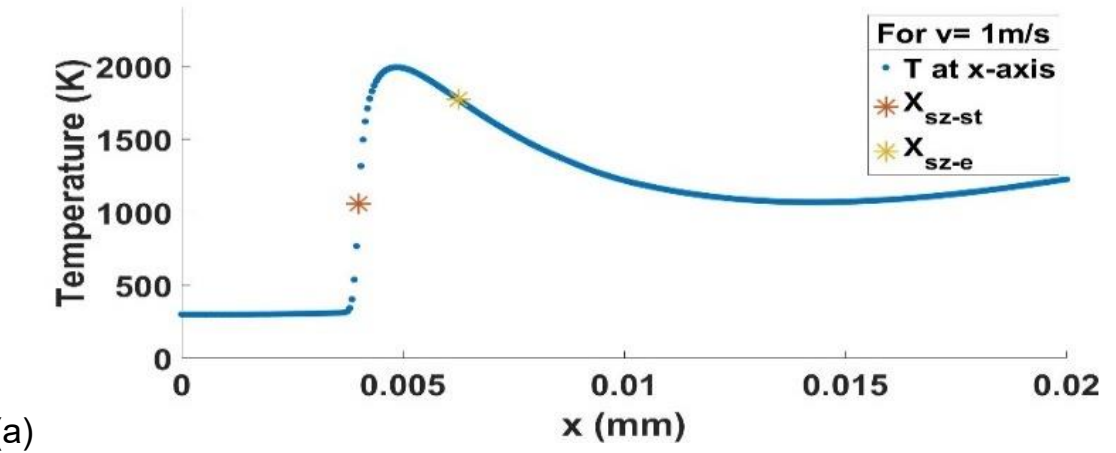

(a) $x(\mathrm{~mm})$

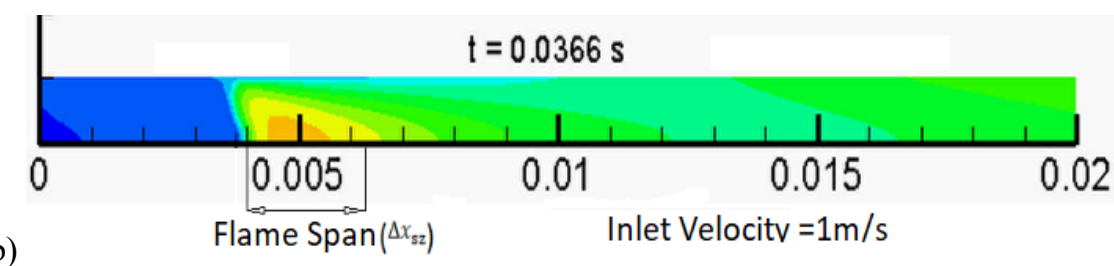

Fig. 3.6: The temperature variation for the stabilized flame with the inlet flow velocity of $1 \mathrm{~m} / \mathrm{s}$ :

(a) the temperature distribution along the $\mathrm{x}$-axis and (b) temperature contour in the simulation domain.

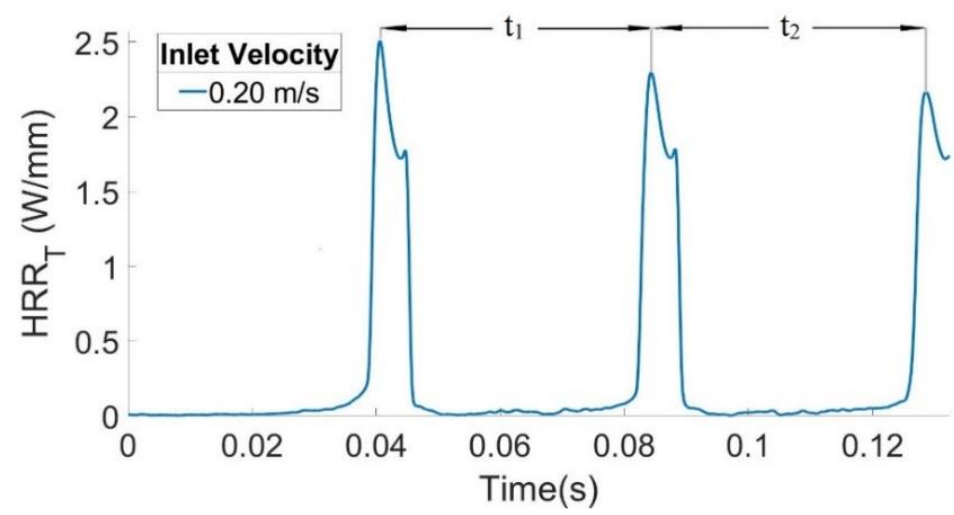

Fig. 3.7: The FRIE period at the inlet velocity of $1 \mathrm{~m} / \mathrm{s}$.

\subsubsection{Flame with repetitive ignition extinction period}

When the velocity of the inlet flow is lower, the flame is not stable. This flame was continuously ignited and extinct after a certain interval of time. This type of flame is defined as a flame with 
repetitive ignition and extinction (FRIE or FREI) which has been seen on other experimental studies with different fuel/air mixture in microscale combustion [33, 39-42], and the time required for a flame to experience two consecutive ignition incidents is defined as the FRIE period ( $\left.\tau_{F R I E}\right)$ for these cases. As shown in Fig. 3.7, the quantities $t_{1}$ and $t_{2}$ are the time period in this case which given as $\tau_{1}=t_{1}$ and $\tau_{2}=t_{2}$. 


\section{Results and analysis}

2D laminar premixed, stochiometric syngas combustion in a microchannel at different conditions is simulated and analyzed in ANSYS Fluent to understand the flame dynamics and combustion characteristics for such a system. This section presents a detailed analysis of the results obtained in my work. Two different cases are considered: (i) the analysis of combustion characteristics for varying inlet velocity and (ii) the analysis of combustion characteristics for varying composition. At first, the simulations are carried on for mixture composition A, which is given in Table 3.1 for eight various inlet velocities, and the results are discussed in the first case given in Sec. 4.1. Then the simulations are carried out for the other two mixture compositions, B and C, presented in Table 3.1 at four various inlet velocities comparing to those of mixture composition A. These results are discussed in the second part of this section, Sec. 4.2.

\subsection{Case 1: Analysis of flame characteristics with respect to inlet velocity}

Premixed syngas combustion is simulated on the given setup with the inlet velocity ranging from 0.1 to $3.0 \mathrm{~m} / \mathrm{s}$. In this case, the syngas mixture (mixture A from Table 3.1) is comprised of $30 \%$ of $\mathrm{CH}_{4}, 5 \%$ of $\mathrm{CO}$, and $65 \%$ of $\mathrm{H}_{2}$. The preheated wall resulted in autoignition downstream, where a $\mathrm{V}$-shape flame kernel formed and started propagating upstream exhibiting a more planar shape. These results are compared and analyzed in terms of the ignition process and flame stability. Here, depending on the inlet velocity, two distinct types of the flame behavior were observed as listed in Table 4.1. For the inlet velocity exceeding $0.2 \mathrm{~m} / \mathrm{s}$, steady combustion was achieved after a certain time interval. For smaller inlet velocities, unstable flames were observed with FRIE. The ignition process in these cases, along with the FRIE and stable flames, will be discussed in the following.

Table 4.1: Classification of flame behavior for various inlet velocities.

\begin{tabular}{|c|c|c|c|c|c|c|c|c|}
\hline Inlet Velocity (m/s) & 0.1 & 0.15 & 0.2 & 0.5 & 0.75 & 1.0 & 1.5 & 3.0 \\
\hline Flame Mode & \multicolumn{3}{|c|}{ FRIE } & \multicolumn{5}{c|}{ Stable } \\
\hline
\end{tabular}

\subsubsection{Ignition process}

Ignition process in premixed syngas combustion starts with syngas-air premixture entering the channel at a constant temperature of $300 \mathrm{~K}$. The imposed temperature gradient on the wall, as explained in Sec. 3.1, facilitates the ignition process by preheating the mixture through conjugate 
heat transfer from the wall to the mixture. In such a preheated mixture, the exothermic chemical reaction starts, and the energy of the system increases, namely, the HRR and $H_{R} R_{T}$ simultaneously grow. The $H R R_{T}$ increases rapidly after some time, reaching its peak value when autoignition occurs. Thereafter, a flame moves and tries to be stabilized when there is a subsequent decrease in $H R R_{T}$. This reduction of the energy of the system is relatively very low making $H R R_{T}$ to become zero like that at the beginning phase, which is dependent on the various condition and will be discussed in Secs. 4.1.2 and 4.1.3.

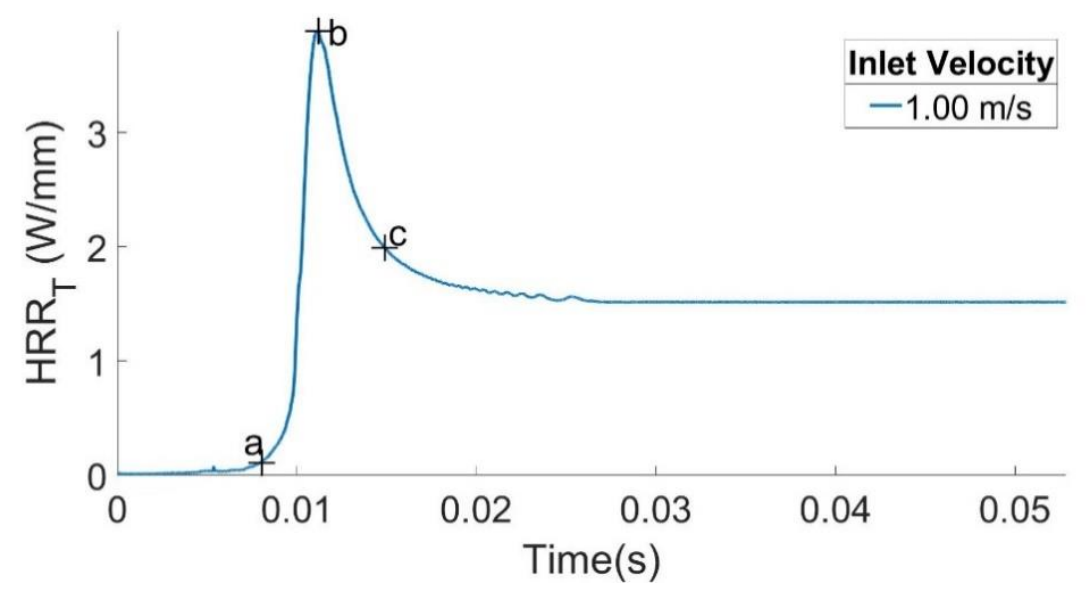

Fig. 4.1: The total heat release rate $\left(H R R_{T}\right)$ versus time for the inlet velocity of $1.0 \mathrm{~m} / \mathrm{s}$.

Figure 4.1 presents the $H R R_{T}$ variations with time for the mixture composition A with the inlet velocity of $1 \mathrm{~m} / \mathrm{s}$. We can observe from this figure that $H R R_{T}=0$ at $t=0$, showing the initial condition of the system, with no fuel and thereby no reaction occurrence at $t=0$. Later, the premixed syngas-air is preheated moving towards the side where a wall has a higher temperature. Then, we reach a state (a), where the energy of the system increases slightly indicating the beginning of an exothermic reaction of the mixture, which is also seen on the temperature contour of this system, Fig. 4.2a, where the temperature of the walls is seen to affect the domain and increase the temperature of the fluid near the higher wall temperature region. After this state, as we can see in Fig. 4.1, there is an abrupt increase in $H R R_{T}$ for a very short time, giving the very steep slope with a peak value at the state (b). From state (a) to state (b), the mixture is heated enough to initiate the radical generating branch chained reaction. This state (b) is defined as the marker of the ignition times $t_{i g}$ in this work as when compared to the temperature contour, a hightemperature region is seen, which means a reaction area is generated, through which the mixture temperature suddenly grows and the unburnt and burnt gases are separated. After point (b), $H R R_{T}$ 
decreases and, as observed in the temperature contour in Fig. 4.2-c as well, a V-shape flame kernel is formed, propagating upstream as its shape becomes more planar. This scenario continues until the flame either reached a stable location or extinguished depending on the operating condition.

\section{Temperature (K)}

(a)

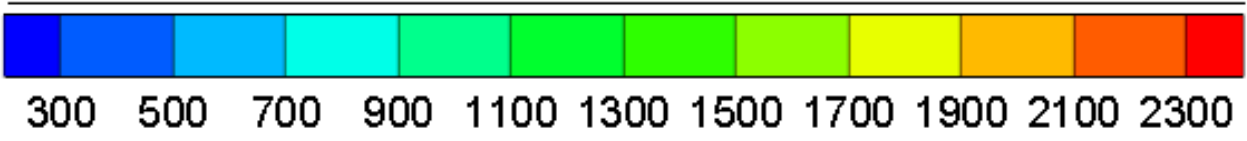

(b)
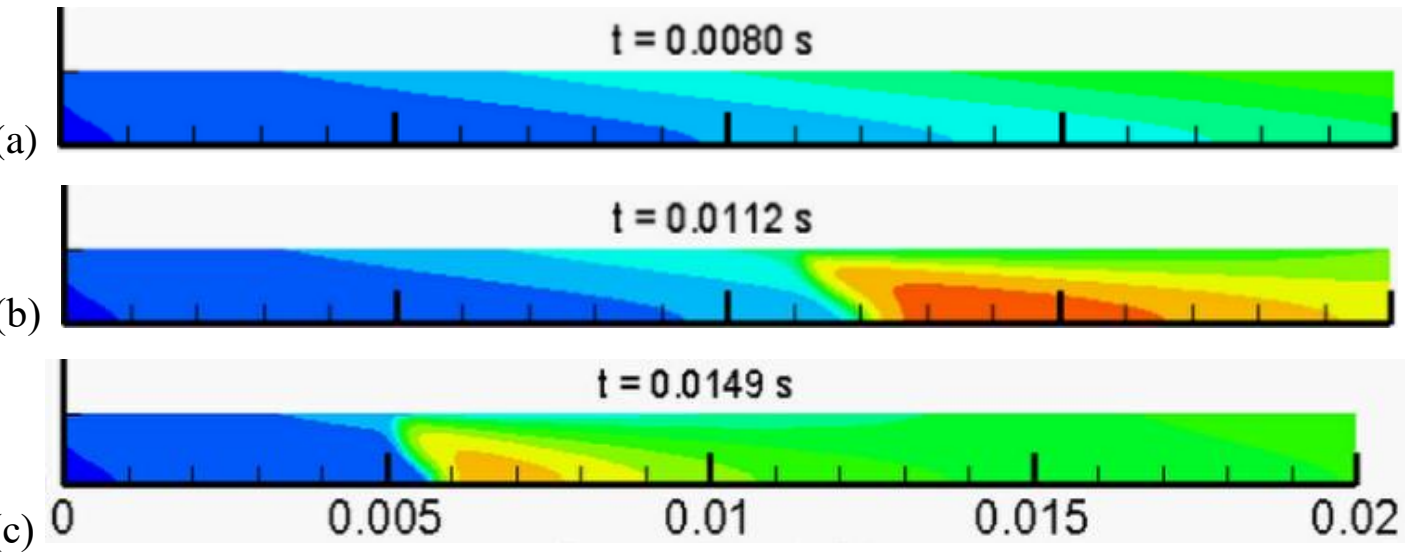

$$
\mathrm{t}=0.0112 \mathrm{~s}
$$

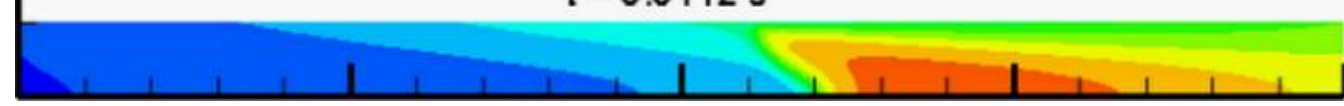

(c)

0.005

Table 4.2: Ignition metrics against inlet velocity.

\begin{tabular}{|c|c|c|c|c|}
\hline \multirow{2}{*}{ Inlet Velocity $(\mathrm{m} / \mathrm{s})$} & Ignition Time $(\mathrm{ms})$ & \multicolumn{2}{|c|}{ Ignition Location $(\mathrm{mm})$} & \multirow{2}{*|}{ Ignition Length (mm) } \\
\cline { 2 - 5 } & $t_{i g}(\mathrm{~s})$ & $x_{i g-s t}$ & $x_{i g-e}$ & $\Delta x_{\mathrm{ig}}$ \\
\hline 0.10 & 77.14 & 6.35 & 9.70 & 3.35 \\
\hline 0.15 & 52.49 & 6.45 & 9.80 & 3.35 \\
\hline 0.20 & 40.56 & 7.95 & 11.60 & 3.65 \\
\hline 0.50 & 18.96 & 9.95 & 13.60 & 3.65 \\
\hline 0.75 & 13.73 & 12.00 & 16.00 & 4.00 \\
\hline 1.00 & 11.17 & 12.00 & 16.80 & 4.80 \\
\hline 1.50 & 8.32 & 13.60 & 19.30 & 5.70 \\
\hline 3.00 & 5.25 & 16.00 & 20.00 & 4.00 \\
\hline
\end{tabular}

This autoignition and flame propagation is seen for all the scenarios tested in this chapter. Thus, the ignition properties are analyzed further to understand more about the combustion phenomena. The ignition time, $t_{\mathrm{ig}}$, the ignition flame locations, $x_{i g-s t}$ and $x_{i g-e}$, and the ignition flame length, $\Delta x_{\text {ig }}$, are computed for all the inlet velocities considered as summarized in Table 4.2. The ignition time diminishes with the inlet velocity, which indicates that the residence time is lower for higher 
inlet velocities such that the syngas-air mixture is preheated faster through the wall which causes the reaction to start earlier and faster. Hence, the flame ignites earlier in the cases with the higher inlet velocities as compared to the cases with the lower inlet velocities. Further, at the higher inlet velocities, the ignition kernel appears further downstream, at a higher wall temperature, which supports the given explanation that a higher inlet velocity means a lower residence time, so the unburnt mixture moves faster to the higher temperature region, where ignition occurs. Moreover, at the higher inlet velocities, the ignition length $\Delta x_{\text {ig }}$ is larger. This indicates that at the higher inlet velocity, the mixture requires higher temperatures and reaction areas to ignite, see also Ref. [35].

\subsubsection{Stable flames}

Two types of flame propagation were observed in this case, when the inlet velocity is varied for the syngas mixture composition considered in this section. After autoignition, the flame started to propagate upstream i.e. from the burnt matter to the unburnt mixture side while becoming more planar. In the case of a higher inlet velocity (which in our case is that exceeding $0.2 \mathrm{~m} / \mathrm{s}$ ), the flame propagated upstream the same way in all cases but eventually became stationary. In Fig. 4.3, we can see the evolution of the $H R R_{T}$ for the inlet velocities in the range from 0.5 to $3.0 \mathrm{~m} / \mathrm{s}$, which gives us a stable flame. This figure confirms the correlation between the inlet velocity and ignition properties; it is demonstrated that for higher inlet velocities, the flame is stabilized faster showing the stabilizing time dependence on the inlet flow velocity as well.

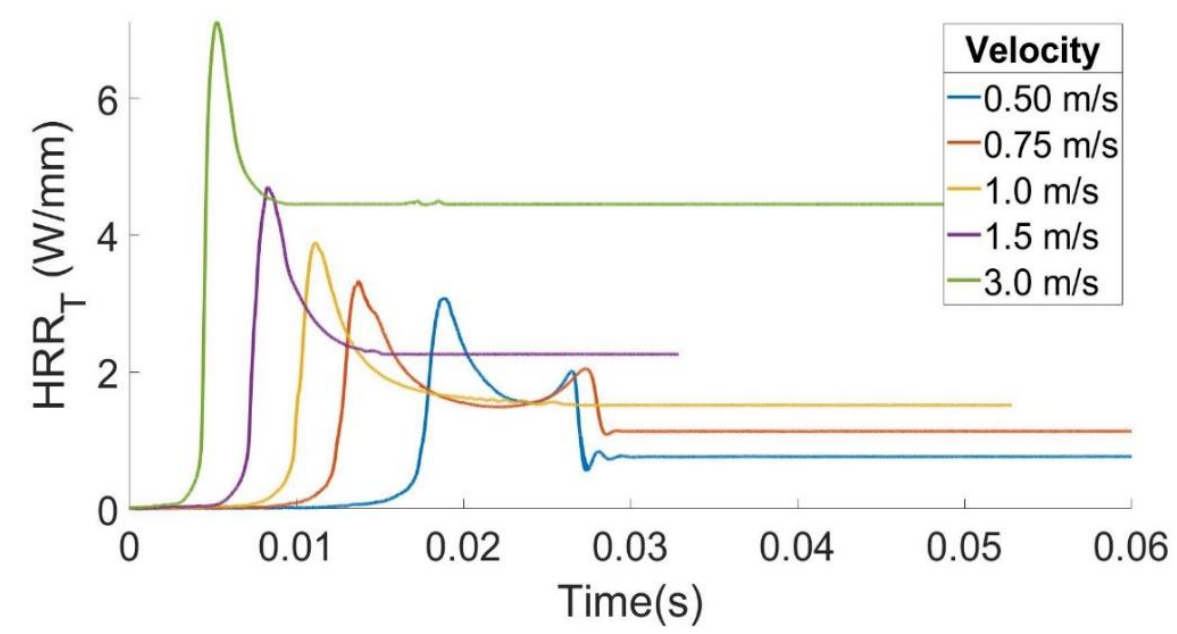

Fig. 4.3: The total heat release rate $\left(H R R_{T}\right)$ versus time for the inlet velocities resulting in a stable flame.

For further analysis of this case, the stable flame is studied by extracting the stable flame properties such as the stabilized flame location $x_{s z-s t}$ and $x_{s z-e}$, and the stabilized flame length, $\Delta x_{\mathrm{sz}}$ which 
is presented in Table 4.3. The stabilization location has been observed to be further from the inlet in case of higher inlet velocity and closer to the inlet for a lower inlet velocity. Due to conjugate heat transfer from the wall to the channel, it was observed that flame stabilization occurred near the higher temperature region, for the higher inlet velocity, and near the lower temperature region, for the lower inlet velocity, for stable mode. This means that for a higher inlet velocity, a higher temperature is required to stabilize a flame.

Table 4.3: The stabilization location for the stable cases

\begin{tabular}{|c|c|c|c|}
\hline \multirow{2}{*}{ Inlet Velocity (m/s) } & \multicolumn{2}{|c|}{ Flame Location (mm) } & Flame Span (mm) \\
\cline { 2 - 4 } & $x_{s z-s t}$ & $x_{s z-e}$ & $\Delta x_{\mathrm{sz}}$ \\
\hline 0.50 & 0.10 & 1.85 & 1.75 \\
\hline 0.75 & 0.10 & 2.35 & 2.25 \\
\hline 1.00 & 4.00 & 6.25 & 2.25 \\
\hline 1.50 & 7.05 & 9.70 & 2.65 \\
\hline 3.00 & 10.70 & 15.35 & 4.65 \\
\hline
\end{tabular}

\subsubsection{Flames with repetitive ignition \& extinction (FRIE)}

Premixed syngas combustion for a given setup with an inlet flow velocity smaller than $0.2 \mathrm{~m} / \mathrm{s}$ produced unstable combustion with FRIE. For these velocities, the flame front propagates further upstream to the locations closer to the inlet, where the wall temperature is not high enough and a flame cannot sustain and, therefore, it extinguishes. On the other hand, since there is a continuous syngas-air mixture entering the channel, the mixture can be reignited again when it reaches a hightemperature region downstream. Such a FRIE phenomenon has been observed in the literature, numerically and experimentally, for various fuels in premixed micro combustion [13, 27, 35].

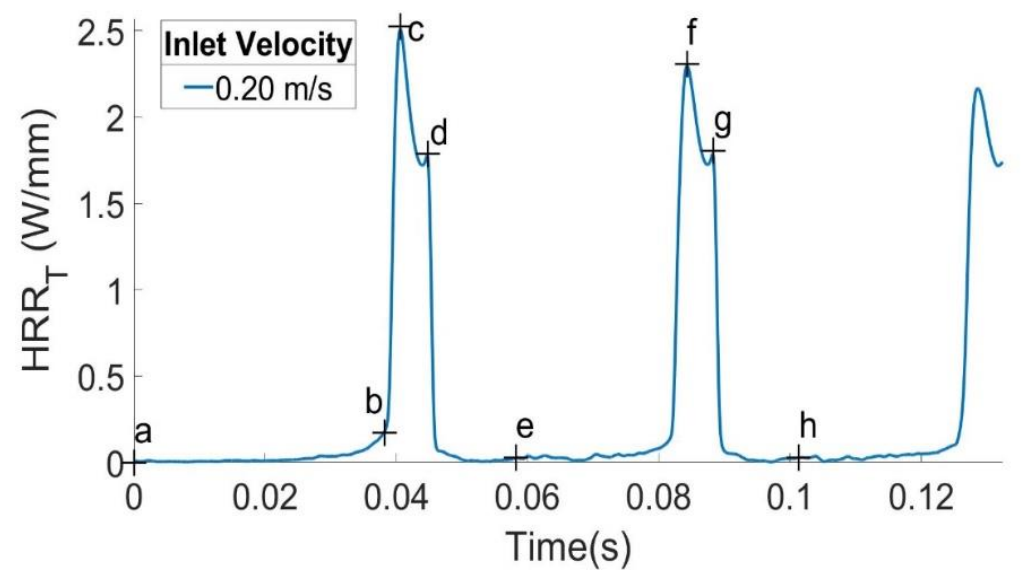

Fig. 4.4: $H R R_{T}$ versus time for a flame with repetitive ignition/extinction (here, the inlet velocity is $0.2 \mathrm{~m} / \mathrm{s}$ ). 
(a)

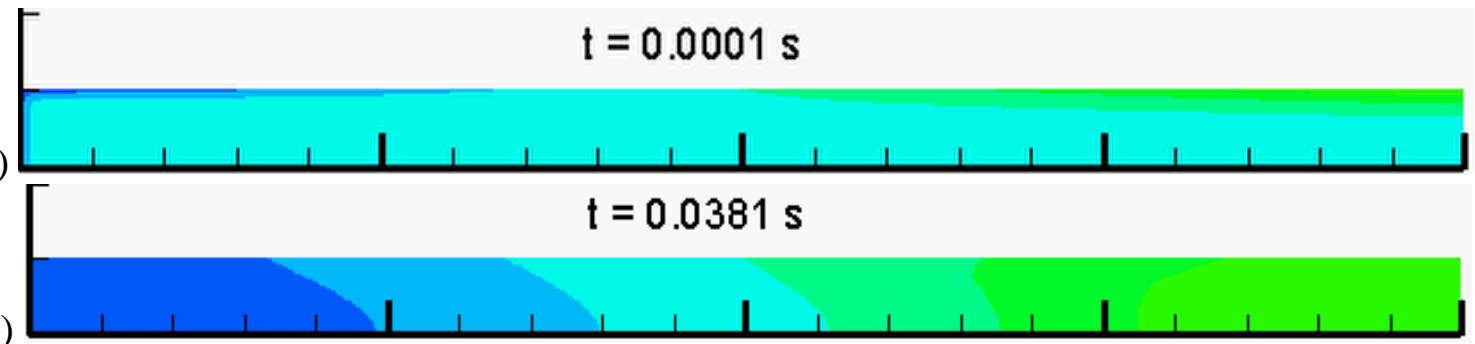

(b)

(c)
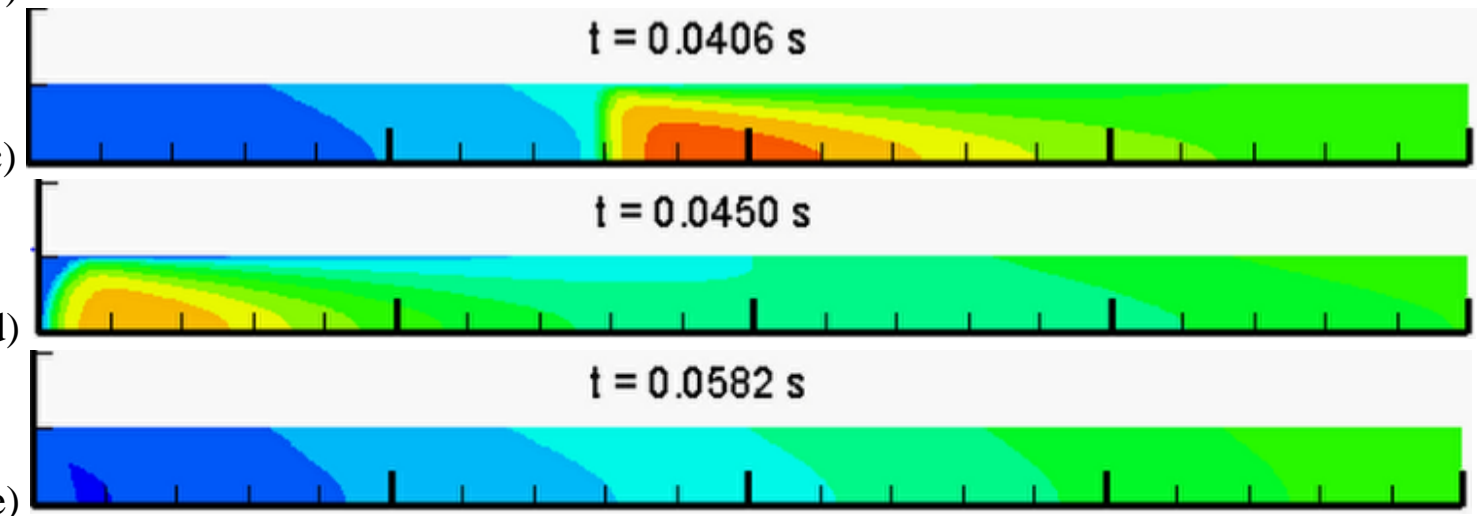

(e)

(f)

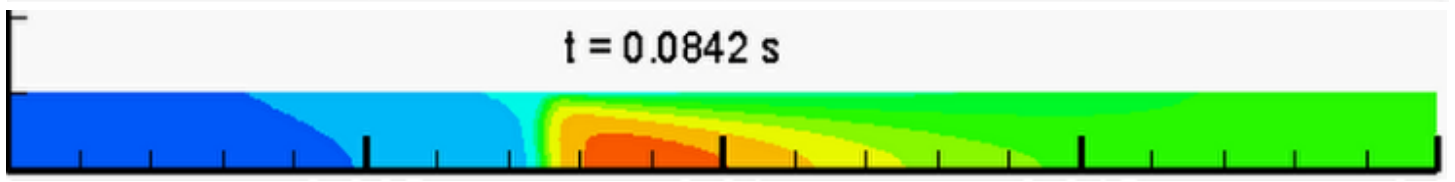

(g)

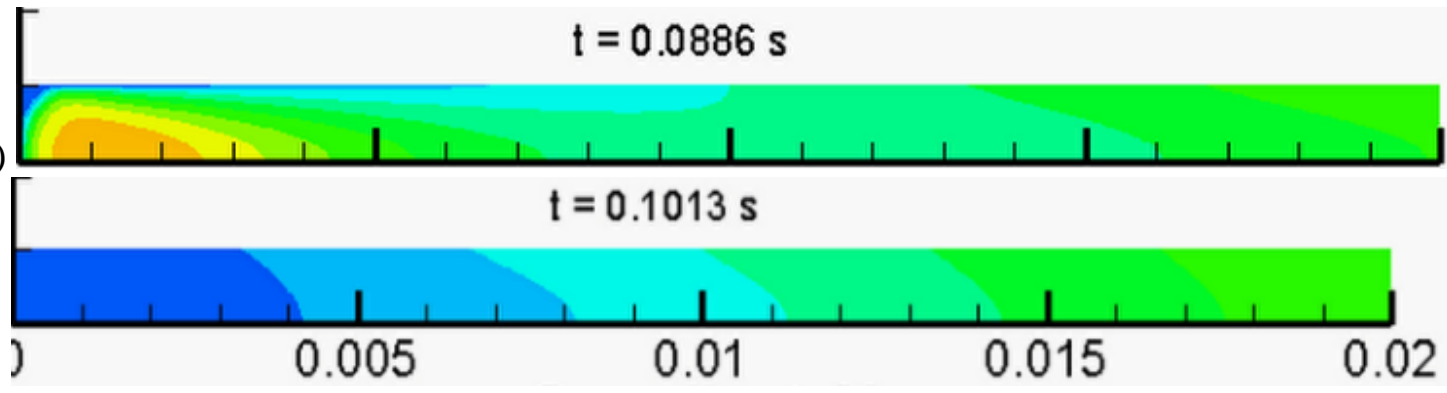

Fig. 4.5: Temperature contours at selected time steps representing flames with FRIE for the inlet velocity of $0.2 \mathrm{~m} / \mathrm{s}$.

To understand the FRIE process for premixed syngas combustion further, the time variations of the $H R R_{T}$ for the FRIE case, with the inlet flow velocity of $0.2 \mathrm{~m} / \mathrm{s}$, are depicted in Fig. 4.4, with the temperature contours corresponding to the instants (a) - (h) shown in Fig. 4.5. From state (a) ( $t=0$; the initial state, where nothing is happening); through state (b) (where the reaction starts but the temperature is not high enough for the reaction rate to grow); to state (c) (where the mixture preheats and the temperature is high enough for a reaction to start and ignition occurs), the scenario is same as that in Sec. 4.1.1, where the ignition process is described. After state (c), Fig. 4.4 shows a slight temperature increased state $(\mathrm{d})$ which, when compared to the respective temperature contour given in Fig. 4.5, shows the very close proximity of a flame to the inlet. A possible reason for this feature could be the following: as the flame propagates towards the inlet, consuming the 
unburnt fuel mixture arriving from the inlet when the flame reaches to a point, where the unburnt fuel concentration is maximum, the reaction rate increases and, hence, $H R R_{T}$ of the system grows too. After state (d), although the fuel level is high in the inlet, the temperature is not high enough near the inlet to sustain this state, so the $H R R_{T}$ drops to zero, which is the state (e). The temperature contour in Fig. 4.5 further supports this explanation as only conjugate wall heat transfer to the domain is observed in the state (e). However, the mixture reignites again farther downstream as seen from the state (e) to state (f) and state (g), and it extinguishes again at state (h) with its respective temperature contour in Fig. 4.5-h. This process continues repeatedly, and a similar trend is observed for the inlet velocities of $0.1 \mathrm{~m} / \mathrm{s}$ and $0.15 \mathrm{~m} / \mathrm{s}$ as well.

Table 4.4: The FRIE period for the corresponding inlet velocities.

\begin{tabular}{|c|c|c|c|}
\hline Inlet Velocity (m/s) & 0.10 & 0.15 & 0.20 \\
\hline$\tau_{F R I E}(\mathrm{~ms})$ & 82.27 & 55.93 & 42.00 \\
\hline
\end{tabular}

This FRIE case is further analyzed and all this ignition time is calculated which is known as FRIE time period $\left(\tau_{F R I E}\right)$ for all three inlet velocities considered. It was further observed that these time periods are the same for each inlet velocity giving us the FRIE with an oscillating time period. The comparison of these time periods is presented in Table 4.4. Similar to the ignition times, the FRIE periods are also found to decrease with the inlet velocity.

\subsection{Case 2: Analysis of flame characteristics with varying composition}

In this case, the variation of the combustion characteristics and flame dynamics are investigated for the three syngas compositions represented in Table 3.1, with the inlet flow velocities ranging from 0.2 to $1.0 \mathrm{~m} / \mathrm{s}$. After the simulations are run for the given inlet velocities, for mixture A, the composition was changed, and the inlet velocity is varied to see the effect of composition at different inlet velocity.

Similar to Sec. 4.1, in all cases, a V-shaped flame kernel is initially formed and then it propagates upstream. The ignition processes are also the same for all compositions as explained in Sec. 4.1.1. The variation of $\mathrm{HRR}_{\mathrm{T}}$ versus time are compared for Cases $\mathrm{A}, \mathrm{B}$ and $\mathrm{C}$ at various inlet flow velocities, with two different types of flame behavior, observed: (i) stable flames and (ii) unstable flames (FRIE), see Fig. 4.6. As the inlet velocity decreases, the autoignition time, $t_{i g}$, grows and 
a flame becomes unstable such that the FRIE phenomenon is observed. In all mixture composition, this limiting velocity is $0.2 \mathrm{~m} / \mathrm{s}$ such that for larger velocities the flame is stabilized.

(a) CASE A

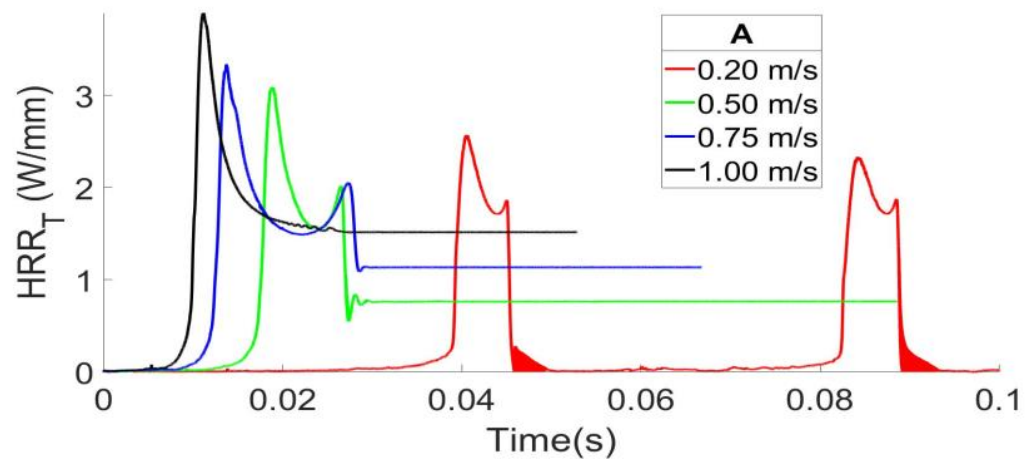

(b) CASE B

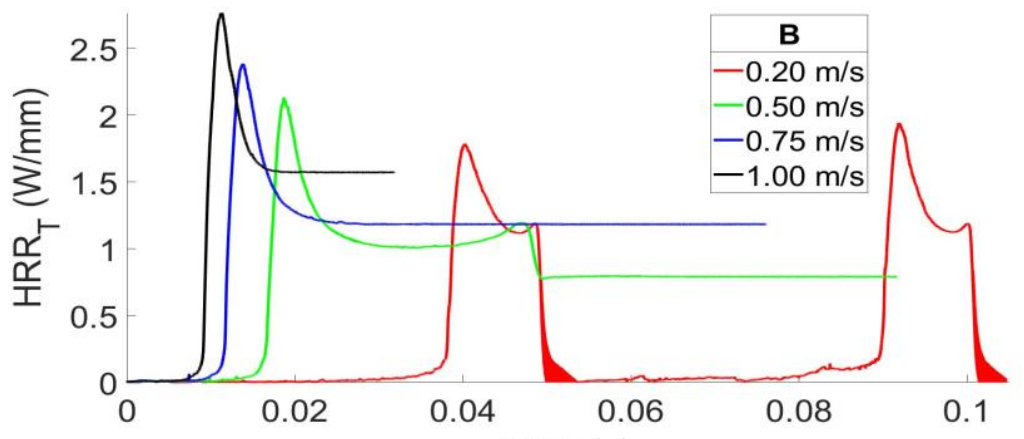

(c) CASE $\mathbf{C}$

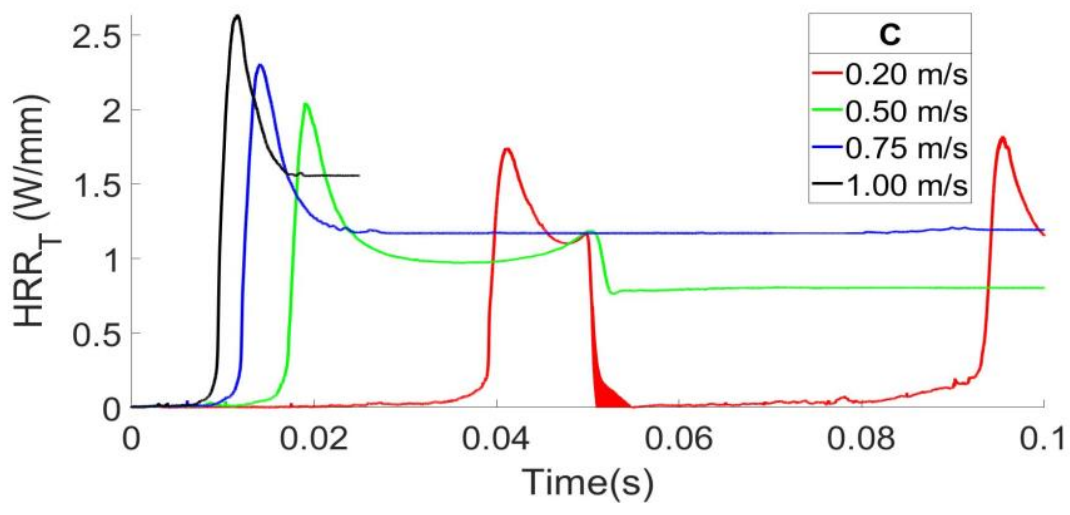

Fig. 4.6: $H R R_{T}$ versus time for the syngas mixture from Table 3.1 at various inlet velocities.

The ignition process is further characterized by its location, $x_{i g-s t}$ and $x_{i g-e}$, and the ignition length, $\Delta x_{\mathrm{ig}}$, which is identified using the axial temperature distribution and its gradients are taken at the autoignition time $t_{i g}$, similar to the previous case which is presented in Table 4.5. It was observed that for all these mixture compositions, the ignition time increases as the inlet velocity decreases. For these mixture compositions, though variations in ignition time are not too high, the ignition proceeds comparatively faster in mixture $\mathrm{C}$ than in mixture $\mathrm{B}$ and followed by mixture $\mathrm{A}$ 
(i.e. $t_{\mathrm{ig}-\mathrm{C}}>\mathrm{t}_{\mathrm{ig}-\mathrm{B}>\mathrm{t}_{\mathrm{ig}-\mathrm{A}}}$. However, the ignition length grows in the reverse order (i.e. $\Delta x_{\mathrm{ig}-\mathrm{A}}>$ $\left.\Delta x_{\mathrm{ig}-\mathrm{B}}>\Delta x_{\mathrm{ig}-\mathrm{C}}\right)$. As for the ignition location, for a higher inlet velocity, in each case, the ignition occurred further from the inlet, i.e. where the temperature distribution is higher due to the imposed wall temperature gradient and further away from the inlet in mixtures $\mathrm{B}$ and $\mathrm{C}$ as compared to $\mathrm{A}$.

Table 4.5: Ignition time and location for all cases.

\begin{tabular}{|c|c|c|c|c|c|}
\hline & Velocity $(\mathrm{m} / \mathrm{s})$ & $t_{i g}(\mathrm{~ms})$ & $x_{i g-s t}(\mathrm{~mm})$ & $x_{i g-e}(\mathrm{~mm})$ & $\Delta x_{\text {ig }}(\mathrm{mm})$ \\
\hline \multirow{3}{*}{ Mixture A } & 0.2 & 40.56 & 7.95 & 11.60 & 3.65 \\
\cline { 2 - 6 } & 0.5 & 18.96 & 9.95 & 13.60 & 3.65 \\
\cline { 2 - 6 } & 0.75 & 13.73 & 12.00 & 16.00 & 4.00 \\
\cline { 2 - 6 } & 1.0 & 11.17 & 12.00 & 16.80 & 4.80 \\
\hline \multirow{3}{*}{ Mixture B } & 0.2 & 40.19 & 8.75 & 12.20 & 3.45 \\
\cline { 2 - 6 } & 0.5 & 18.66 & 11.35 & 15.50 & 4.15 \\
\cline { 2 - 6 } & 0.75 & 13.80 & 12.15 & 15.80 & 3.65 \\
\hline & 1.0 & 11.31 & 12.75 & 16.80 & 4.05 \\
\cline { 2 - 6 } & 0.2 & 41.20 & 9.15 & 12.15 & 3.00 \\
\cline { 2 - 6 } & 0.5 & 19.15 & 10.35 & 13.80 & 3.45 \\
\cline { 2 - 6 } & 0.75 & 14.15 & 12.80 & 16.55 & 3.75 \\
\cline { 2 - 6 } & 1.0 & 11.65 & 13.30 & 17.70 & 4.40 \\
\hline
\end{tabular}

Table 4.6: Ignition temperature for all cases.

\begin{tabular}{|c|c|c|}
\hline \multirow{4}{*}{ Mixture A } & Velocity $(\mathrm{m} / \mathrm{s})$ & Ignition Flame Temperature $(\mathrm{K})$ \\
\cline { 2 - 3 } & 0.2 & 2246.315 \\
\cline { 2 - 3 } & 0.5 & 2268.867 \\
\cline { 2 - 3 } & 0.75 & 2287.44 \\
\hline \multirow{4}{*}{ Mixture B } & 1 & 2259.89 \\
\cline { 2 - 3 } & 0.2 & 2127.811 \\
\cline { 2 - 3 } & 0.5 & 2138.321 \\
\cline { 2 - 3 } & 0.75 & 2131.741 \\
\hline \multirow{3}{*}{ Mixture C } & 1 & 2119.286 \\
\cline { 2 - 3 } & 0.2 & 2158.642 \\
\cline { 2 - 3 } & 0.5 & 2130.371 \\
\cline { 2 - 3 } & 0.75 & 2166.656 \\
\hline
\end{tabular}

Further, the ignition flame temperature was calculated as they are listed in Table 4.6. The flame temperature for different composition such as $\mathrm{H}_{2} /$ air, $\mathrm{CH}_{4} /$ air and $\mathrm{CO} /$ air individually is 2483.15 $\mathrm{K}, 2223.15 \mathrm{~K}$, and $2394 \mathrm{~K}$, respectively. As given in Table 4.6, for mixture A with $65 \%$ of $\mathrm{H}_{2}$, the flame temperature is closer to that of hydrogen. Similarly, for mixtures B and C, the $\mathrm{CH}_{4}$ fractions 
are $70 \%$ and $60 \%$, respectively, such that the flame temperature is closer to the $\mathrm{CH}_{4} /$ air flame temperature. This justifies the role of composition effect on premixed syngas combustion.

Table 4.7: The stabilized flame location.

\begin{tabular}{|c|c|c|c|c|}
\hline & Velocity $(\mathrm{m} / \mathrm{s})$ & $x_{s Z-s t}(\mathrm{~mm})$ & $x_{s Z-e}(\mathrm{~mm})$ & $\Delta x_{s Z}(\mathrm{~mm})$ \\
\hline \multirow{3}{*}{ Mixture A } & 0.5 & 0.10 & 1.85 & 1.75 \\
\cline { 2 - 5 } & 0.75 & 0.10 & 2.35 & 2.25 \\
\cline { 2 - 5 } & 1.0 & 4.00 & 6.25 & 2.25 \\
\hline \multirow{3}{*}{ Mixture B } & 0.5 & 0.10 & 2.20 & 2.10 \\
\cline { 2 - 5 } & 0.75 & 7.15 & 9.40 & 2.25 \\
\cline { 2 - 5 } & 1.0 & 9.15 & 11.60 & 2.45 \\
\hline \multirow{3}{*}{ Mixture C } & 0.5 & 0.10 & 2.20 & 2.10 \\
\cline { 2 - 5 } & 0.75 & 7.50 & 9.65 & 2.15 \\
\cline { 2 - 5 } & 1.0 & 9.50 & 12.00 & 2.50 \\
\hline
\end{tabular}

Similarly, for the stable cases, the location where the flame stabilizes, $x_{s z-s t}, x_{s z-e}$, and the stable flame length, $\Delta x_{\mathrm{sz}}$, calculated in the same manner as the ignition location. From Table 4.7, it is observed that, for larger inlet velocities, the stabilized flame localizes further away from the inlet, where the wall temperature is higher, which provides a similar analysis for mixtures $\mathrm{B}$ and $\mathrm{C}$ to that of A presented in section 4.1.2. For the inlet velocities from 0.5 and $0.75 \mathrm{~m} / \mathrm{s}$ for Case A, and $0.5 \mathrm{~m} / \mathrm{s}$ for Cases B and C, the flame is stabilized starting from the inlet, which is also the cases with a minor peak seen in Fig. 4.6 after the ignition. As the inlet velocity decreases, the flame moves closer to the inlet until it cannot sustain anymore due to lower wall temperatures. Further, for Case A, the flame stabilizes closer to the inlet with a longer flame span than that of B and C.

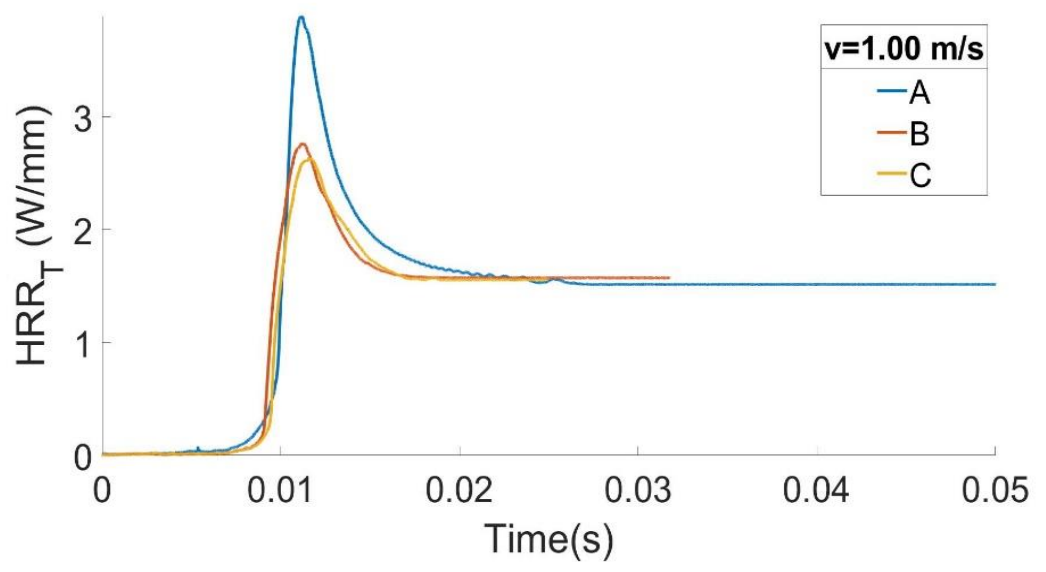

Fig. 4.7: $H R R_{T}$ versus time for the stable flame cases. 
To study the effect of syngas composition on its flame behavior at various velocities $H R R_{T}$ is calculated and compared for all three cases at two different inlet velocities: (i) $1 \mathrm{~m} / \mathrm{s}$, Fig. 4.7, where all three mixture compositions resulted in stable flames, and (ii) $0.2 \mathrm{~m} / \mathrm{s}$, Fig. 4.8, where the FRIE phenomenon was observed for all three mixture compositions. Fig. 4.7 shows that Case A (a mixture containing $65 \%$ of $\mathrm{H}_{2}$ ) gives larger $H R R_{T}$ as compared to the other two cases because of the high energy density of $\mathrm{H}_{2}$. In addition to this, we can observe that flame stabilization takes longer in Case A than in Case B and Case C.

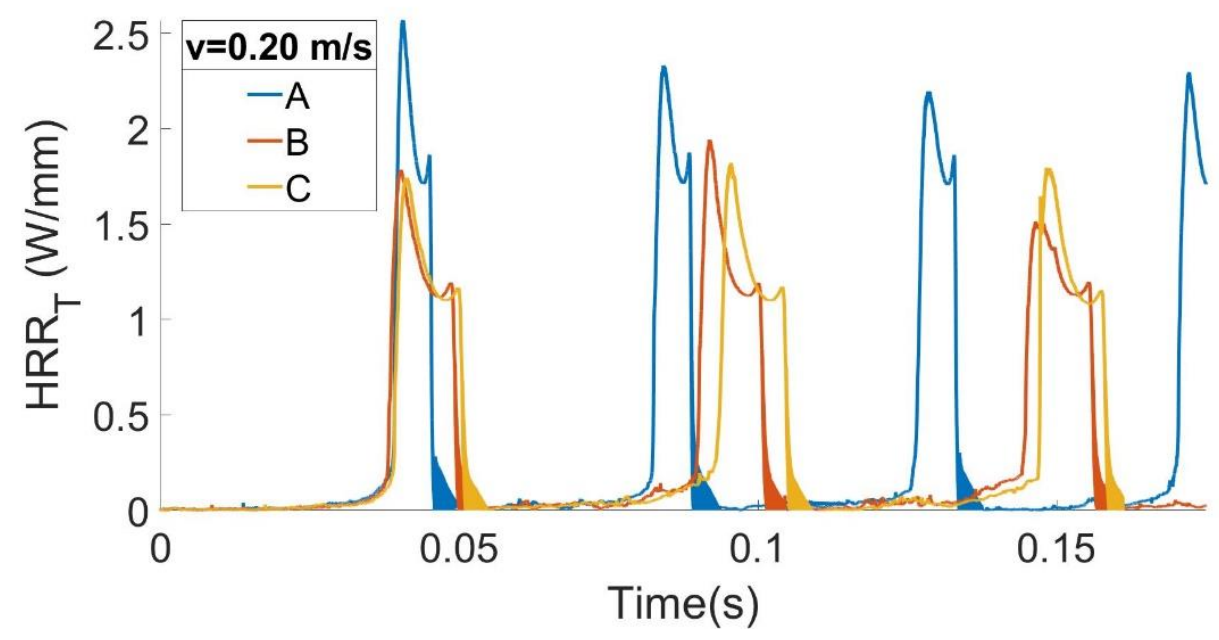

Fig. 4.8: $H R R_{T}$ versus time for the FRIE cases

Similar to Fig. 4.7, the $H R R_{T}$ evolution is plotted in Fig. 4.8 for Cases A, B and C, with the inlet velocity of $0.2 \mathrm{~m} / \mathrm{s}$, thereby representing the unstable cases, where each ignition is followed by extinction in a repeated manner. These repetitive ignition times are given in Table 4.8 for all cases (here, $t_{\text {igx }}$ represents the $x^{\text {th }}$ ignition time whereas $t_{\text {igyx }}$ marks the difference between the $y^{\text {th }}$ and $x^{\text {th }}$ ignition time, i.e. $t_{\text {igyx }}=t_{\text {igy }}-t_{\text {igx }}$ ). It is seen that the consecutive ignition times grow in Case $\mathrm{B}$ and diminish in Case C (by $2 \mathrm{~ms}$ ), while in Case A (oscillating flame) remain almost the same.

Table 4.8: Ignition time for the FRIE cases given in Fig. 4.8.

\begin{tabular}{|c|c|c|c|c|c|}
\hline & $t_{i g 1}(\mathrm{~ms})$ & $t_{i g 2}(\mathrm{~ms})$ & $t_{i g 3}(\mathrm{~ms})$ & $\Delta t_{\text {ig21 }}(\mathrm{ms})$ & $\Delta t_{\text {ig32 }}(\mathrm{ms})$ \\
\hline Mixture A & 40.4 & 84.3 & 128.6 & 43.9 & 44.3 \\
\hline Mixture B & 40.2 & 92.0 & 146.5 & 51.8 & 54.5 \\
\hline Mixture C & 41.3 & 95.6 & 148.2 & 54.3 & 52.6 \\
\hline
\end{tabular}




\section{Conclusions and recommendations}

\subsection{Conclusions}

Syngas/air premixed combustion in micro-channels is studied numerically with detailed chemistry to understand the dynamics and combustion characteristics at micro scales. The problems that are observed in microscale combustion such as conjugate heat loss through the wall is addressed by imposing temperature gradient on the wall with the purpose of preheating the mixture. The inlet flow velocity is varied for the domain to observe its effect on various combustion parameters and the simulations are run to see the composition effect on the same parameters and compared. Two different flame phenomena (stable flames and FRIE) were observed. The stable flame was seen for high velocities ranging from 0.5 to $3 \mathrm{~m} / \mathrm{s}$, while the FRIE phenomenon was found for the velocity range from 0.1 to $0.2 \mathrm{~m} / \mathrm{s}$. In all cases, the ignition time, the ignition location and length are analyzed and the flame dynamics in both stable and unstable cases were characterized. Further stabilization characteristics such as the stabilization flame location, with its starting and ending location, as well as the stabilization length are also analyzed for the stable flame case while the FRIE time period is scrutinized.

The second type of analysis is carried out for three different mixture composition, composition A (30\% of $\mathrm{CO}, 5 \%$ of $\mathrm{CH}_{4}$, and $65 \%$ of $\mathrm{H}_{2}$ ), composition $\mathrm{B}\left(70 \%\right.$ of $\mathrm{CO}, 5 \%$ of $\mathrm{CH}_{4}$, and $25 \%$ of $\left.\mathrm{H}_{2}\right)$ and composition $\mathrm{C}\left(60 \%\right.$ of $\mathrm{CO}, 10 \%$ of $\mathrm{CH}_{4}$, and $30 \%$ of $\left.\mathrm{H}_{2}\right)$ to evaluate the composition effects on different combustion properties as well as the flame dynamics. In terms of composition, in stable cases, Case A showed more variations in terms of the total heat release, stabilization time, location and flame span as compared to Case B and that of Case C. Similarly, for unstable cases, the difference in consecutive ignition times varies for all the cases where Case A (with a higher fraction of $\mathrm{H}_{2}$ ) shows a flame oscillating in terms of ignition and extinction about some time and it has a higher total heat release in the system. Thus, Case A exhibited significant change in the combustion characteristics such as the flame length and span, the stabilization and ignition time and the FRIE time period, as compared to Cases B and C. Here, case A which has higher hydrogen percentage shows a significant difference compared to other two cases, which confirms the major role and dominance of hydrogen in syngas combustion. 


\subsection{Recommendations}

From this study, dependence of a combustion parameter on an inlet velocity is observed which includes the stability of the flame as well. For different microscale combustion system, the inlet velocity range for the system needs to be determined to ensure the combustion is occurring at a steady state to get the efficient outcome. Different ignition and stabilization parameters depend on the inlet velocity, so for the microscale system, the inlet velocity can be used as a means to compute the ignition (faster ignition or slower ignition) of the system according to the necessity. Moreover, different variation in composition effect on the syngas combustion characteristics is not too high, but different kind of emission depends on this parameter. So, it is recommended to study composition variation when used in microscale.

\subsection{Future works}

Further analysis can be done in this microscale system with premixed syngas/air mixture, namely:

- The outlet exhaust or the product of the system needs to be computed to study the emissions at different inlet velocity and different composition for this system.

- Further composition analysis and its effects need to be studied with other compositions such as inert gases, propane, etc. as real syngas mixture contains these components as well.

- Full channel domain analysis for the 3D domain can be carried out and the results can be compared with the $2 \mathrm{D}$.

- Impacts of other parameters such as height, different temperature gradients, pressure on the channel, etc. can also be studied. 


\section{References}

[1] A.C. Fernandez-pello, "Micropower generation using combustion: Issues and approaches," Proceedings of the Combustion Institute, vol. 29, no. 1, pp. 883-899, 2002.

[2] K.L. Zhang, S.K. Chou and S. Ang, "Development of a low-temperature co-fired ceramic solid propellant microthruster," Journal of Micromechanics and Microengineering, vol. 15, no. 5, pp. 944-952, 2005.

[3] Y. Ju and K. Maruta, "Microscale combustion: Technology development and fundamental research," Progress in Energy and Combustion Science, vol. 37, no. 6, pp. 669-715, 2011.

[4] R.A. Yetter, V. Yang, M.-H. Wu, Y. Wang, D. Milius, A. Ilhan and F.L. Dryer, "Combustion issues and approaches for chemical microthrusters," Advancements in energetic materials and chemical propulsion., vol. 6, no. 4, pp. 32-41, 2007.

[5] J. Vican, B.F. Gajdeczko, F.L. Dryer, D.L. Milius, I. Aksay and R.A. Yetter, "Development of a microreactor as a thermal source for microelectromechanical systems power generation," Proceedings of the Combustion Institute, vol. 29, no. 1, pp. 909-916, 2002.

[6] N.I. Kim, S. Kato, T. Kataoka, T. Yokomori, S. Maruyama, T. Fujimori and K. Maruta, "Flame stabilization and emission of small Swiss-roll combustors as heaters," Combustion and Flame, vol. 141, no. 3, pp. 229-240, 2005.

[7] C.M. Miesse, R.I. Masel, C.D. Jensen, M.A. Shannon and M. Short, "Submillimeter-scale combustion," AlChe Journal, vol. 50, no. 12, pp. 3206-3214, 2004.

[8] M.-H. Wu, Y. Wang, V. Yang and R. A. Yetter, "Combustion in meso-scale vortex chambers," Proceedings of the Combustion Institute, vol. 31, no. 2, pp. 3235-3242, 2007.

[9] S.A. Lloyd and F. Weinberg, "A burner for mixtures of very low heat content," Nature, vol. 251, pp. 47-49, 1974.

[10] F. Weinberg, "Combustion temperatures: The future?," Nature, vol. 233, pp. 239-241, 1971.

[11] S. Jejurkar and D.P. Mishra, "A review of recent patents on micro-combustion and applications," Recent Patents on Engineering, vol. 3, no. 3, pp. 194-209, 2009.

[12] V. Akkerman, V. Bychkov, A. Petchenko and L.-E. Eriksson, "Flame oscillations in tubes with nonslip at the walls," Combustion and Flame, vol. 145, no. 4, pp. 675-687, 2006. 
[13] M. Ayoobi and I. Schoegl, "Numerical analysis of flame instabilities in narrow channels: Laminar premixed methane/air combustion, "International Journal of Spray and Combustion Dynamics, vol. 9, no. 3, pp. 155-171, 2017.

[14] P.R. Resende, M. Ayoobi and A.M. Afonso, "Numerical investigations of micro-scale diffusion combustion: A brief review," Applied Sciences, vol. 9, no. 16, p. 3356, 2019.

[15] V.V. Bychkov and M.A. Liberman, "Dynamics and stability of premixed flames," Physics Reports, vol. 325, pp. 115-237, 2000.

[16] N.F. Othman and M.H. Boosroh, "Effect of $\mathrm{H} 2$ and $\mathrm{CO}$ contents in syngas during combustion," IOP Conference Series: Earth and Environmental Science, vol. 32, no. 12037, pp. 1-5, 2016.

${ }_{[17]}$ R.A. El-Nagar and A.A. Ghanem, "Syngas production, properties, and its importance," in Sustainable Alternative Syngas Fuel, London,UK, IntechOpen, 2019.

[18] D.C. Walther and J. Ahn, "Advances and challenges in the development of power-generation systems at small scales," Progress in Energy and Combustion Science, vol. 37, no. 5, pp. 583-610, 2011.

[19] L.D. Schimdt and P. Dauenhauer, "Syngas production using a biomass gasification process," University of Minnesota-Office for Technology Commecialization, Case no. z07080, 2013.

[20] R.J. Varghese, H. Kolekar, V. Hariharan and S. Kumar, "Effect of CO content on laminar burning velocities of syngas-air premixed flames at elevated temperatures," Fuel, vol. 214, pp. 144-153, 2018.

[21] R. Kumar and G. Koroll, "Carbon monoxide-hydrogen combustion characteristcs in severe accident containment conditions," Nuclear Energy Agency: Committee on the Safety of Nuclear Installations, Paris, France, 2000.

[22] V. Raibhole and S. Sapali, "Simulation and parametric analysis of cryogenic oxygen plant for biomass gasification," Mechanical Engineering Research, vol. 2, pp. 97-107, 2012.

[23] K.T.d.C. Roseno, R.M.d.B. Alves, R. Giudici and M. Schmal, "Syngas production using natural gas from the environmental point of view," in Biofuels - State of Development, London,UK, IntechOpen, 2018, pp. 273-290. 
[24] L. Wei, L. Pordesimo, S.F. To, C. Herndon and W. Batchelor, "Evaluation of micro-scale syngas production costs through modeling," Transaction of American Society of Agricultural Engineers, vol. 52, no. 5, pp. 1649-1659, 2009.

[25] K.J. Whitty, H. Zhang and E.G. Eddings, "Emissions from syngas combustion," Combustion Science and Technology, vol. 180, no. 6, pp. 1117-1136, 2008.

[26] G. Pizza, C.E. Frouzakis, J. Mantzaras, A.G. Tomboulides and K. Boulouchos, "Dynamics of premixed hydrogen/air flames in microchannels," Combustion and Flame, vol. 152, no. 3, pp. 433-450, 2008.

[27] N. Kim and K. Maruta, "A numerical study on propagation of premixed flames in small tubes," Combustion and Flame, vol. 146, no. 1-2, pp. 283-301, 2006.

[28] S. Karagiannidis, J. Mantzaras, G. Jackson and K. Boulouchos, "Hetero-/homogeneous combustion and stability maps in methane-fueled catalytic microreactors," Proceedings of the Combustion Institute, vol. 31, no. 2, pp. 3309-3317, 2007.

[29] D. Norton and D. Vlachos, "Combustion characteristics and flame stability at the microscale: a CFD study of premixed methane/air mixtures," Chemical Engineering Science, vol. 58, no. 21, pp. 4871-4882, 2003.

[30] F.A. Munir and M. Mikami, "A numerical study of propane-air combustion in meso-scale tube combustors with concentric rings," Journal of Thermal Science and Technology, vol. 10, no. 1, pp. 1-12, 2015.

[31] S. Konakov, S. Dzyubanenko and V. Krzhizhanovskaya, "Computer simulation aproach in development of propane-air combustor microreactor," Procedia Computer Science, vol. 101, pp. 76-85, 2016.

[32] W. Wang, Z. Zuo and J. Liu, "Experimental study and numerical analysis of the scaling effect on the flame stabilization of propane/air mixture in the micro-scale porous combustor," Energy, vol. 174, pp. 509-518, 2019.

[33] A. Brambilla, M. Schultze, C.E. Frouzakis, J. Mantzaras, R. Bombach and K. Boulouchos, "An experimental and numerical investigation of premixed syngas combustion dynamics in mesoscale channels with controlled wall temperature profiles," Proceedings of the Combustion Institute, vol. 35, no. 3, pp. 3429-3437, 2015. 
[34] J. Federici and D. Vlachos, "Experimental studies on syngas catalytic combustion on Pt/Al2O3 in a microreactor," Combustion and Flame, vol. 158, no. 12, pp. 2540-2543, 2011.

[35] A. Takbiri-Borujeni and M. Ayoobi, "Application of physics-based machine learning in combustion modeling," in $11^{\text {th }}$ US National Combustion Meeting, Pasadena, CA, Mar. 2019.

[36] "ANSYS Fluent," ANSYS, [Online]. Available: https://www.ansys.com/. [Accessed 2019].

[37] R. Balasubramanian and N. K. Gupta, "ANSYS technology workshop on computational fluid dynamics," ANSYS, Sept. 28-29 2018. [Online]. Available: https://www.iitr.ac.in/ansyscfd/.

[38] "Chemical-Kinetic Mechanisms for Combustion Applications", San Diego Mechanism, Mechanical and Aerospace Engineering (Combustion Research), University of California at San Diego," [Online]. Available: http://combustion.ucsd.edu.

[39] K. Maruta, T. Kataoka, N.I. Kim, S. Minaev and R. Fursenko, "Characteristics of combustion in a narrow channel with a temperature gradient," Proceedings of Combustion Institute, vol. 30, pp. 2429-2436, 2005.

[40] K. Maruta, J. Parc, K. Oh, T. Fujimori, S. Minaev and R. Fursenko, "Characteristics of microscale combustion in a narrow heated channel," Combustion, Explosion and Shock Waves, vol. 40, no. 5, pp. 516-523, 2004.

[41] A.D. Stazio, C. Chauveau, G. Dayma and P. Dagaut, "Oscillating flames in microcombustion," Combustion and Flame, vol. 167, pp. 392-394, 2016.

[42] M. E. Baumgardner, "Microreactor combustion of simple hydrocarbons," in $11^{\text {th }} U . S$. National Combustion Meeting, Pasadena, CA, March, 2019. 